\title{
A direct carbon solid oxide fuel cell operated on a plant derived biofuel with natural catalyst
}

Weizi Cai ${ }^{\mathrm{a}, \mathrm{b}}$, Qian Zhou ${ }^{\mathrm{a}}$, Yongmin Xie ${ }^{\mathrm{a}, \mathrm{c}}$, Jiang Liu ${ }^{\mathrm{a}, \mathrm{b},{ }^{*}}$, Guohui Long ${ }^{\mathrm{d}}$, Shuang Cheng ${ }^{\mathrm{a}}$, Meilin Liu ${ }^{\mathrm{a}, \mathrm{e}}$

${ }^{a}$ New Energy Research Institute, School of Environment and Energy, South China University of Technology, 382 East Road, Higher Education Mega Center, Guangzhou 510006, P.R. China.

${ }^{b}$ The Key Laboratory of Fuel Cell Technology of Guangdong Province, School of Chemistry and Chemical Engineering, South China University of Technology, Guangzhou 510641, P.R. China.

${ }^{c}$ School of Metallurgy and Chemical Engineering, Jiangxi University of Science and Technology, Ganzhou 341000, P.R. China

${ }^{\mathrm{d}}$ College of Life Science, Jilin Agricultural University, Xincheng Road 1118, Changchun 130018, P.R. China.

${ }^{\mathrm{e}}$ School of Materials Science and Engineering, Georgia Institute of Technology, 771Ferst Drive, Atlanta, GA 30332-0245, USA.

\begin{abstract}
Biochar derived from orchid tree leaves is utilised as the fuel of a direct carbon solid oxide fuel cell (DC-SOFC), with yttrium stabilized zirconia (YSZ) as electrolyte and cermet of silver and gadolinium doped ceria (Ag-GDC) as the material of both *Corresponding author: Tel.: +86 2022236168 , Fax: +86 2022236168 E-mail: jiangliu@scut.edu.cn
\end{abstract}


cathode and anode, operating without any liquid medium or feeding gas. The performance of the DC-SOFC operated on the leaf char is higher than that operated on the best reported carbon fuel for DC-SOFCs, Fe-loaded activated carbon. XRD, Raman spectroscopy, SEM and EDX are applied to characterize the leaf char. It turns out that the leaf char is with porous structure and there is much $\mathrm{Ca}$ along with some $\mathrm{K}$ and $\mathrm{Mg}$ uniformly distributing in the leaf char. The effects of the naturally existing alkaline earth metal and alkaline metal and their distribution on the performance of the DC-SOFCs operated on the leaf char are analyzed in detail.

Keywords: Biofuel; Natural catalyst; Solid oxide fuel cell; Boudouard reaction; Direct carbon

\section{Introduction}

Biomass, most often referring to plants or plant-derived materials, is a renewable energy source in which chemical energy, converted from solar energy through photosynthesis of plants, is stored. As the greenhouse gas $\mathrm{CO}_{2}$ is captured from ambient air by plants during photosynthesis, biomass is practically a carbon neutral resource. The bioenergy captured by land plants is 3-4 times greater than human energy demands [1]. Biomass is becoming an important alternative to fossil fuels and providing an increasing supplement to the world energy demand. 
Biofuels are produced from hydrocarbon-rich biomass by thermal, chemical or biochemical conversion processes. Biofuels, such as biogas and biochar, can be directly used in fuel cells. A fuel cell converts chemical energy of fuels into electricity through electrochemical process, with high electrical conversion efficiency [2]. Fuel cells operated with hydrogen fuel have been widely investigated. However, hydrogen is expensive and has the problem of safety and delivering. Therefore, hydrocarbon fuels (carbon containing fuels) have been considered, especially for high-temperature fuel cells such as molten carbonate fuel cells (MCFCs) [3, 4] and solid oxide fuel cells (SOFCs) [5-8]. Recently, direct carbon fuel cells (DCFCs) which use solid carbon as the fuel, have attracted much attention [9-14]. A DCFC converts the chemical energy of carbon directly to electricity with a theoretical efficiency (the Gibbs energy change of reaction $\mathrm{C}+\mathrm{O}_{2}=\mathrm{CO}_{2}$ divided by its enthalpy change, $\Delta G / \Delta H$ ) slightly higher than $100 \%$. DCFCs can be classified in terms of electrolyte: molten hydroxide [15-17], molten carbonate [18], and solid oxide. When solid oxide electrolyte is used in a DCFC, molten carbonate or liquid metal is generally added into the anode chamber for carbon delivering [19-22]. Such DCFCs are also called as hybrid DCFCs (HDCFCs).

Biochar, a carbon rich substance derived from biomass through thermal pyrolysis, has been used as the fuel of DCFCs. Halouani's group applied biochar derived from almond shell as the fuel of a DCFC with molten carbonate electrolyte and obtained a peak power density of $127 \mathrm{~mW} \mathrm{~cm}^{-2}$ at $750{ }^{\circ} \mathrm{C}$ [23]. 
A DCFC operated on biochar from carbonization of corn cob has been reported to give a maximum power output of $185 \mathrm{~mW} \mathrm{~cm}^{-2}$ at $750{ }^{\circ} \mathrm{C}$ [24]. Irvine's group $[25,26]$ has systematically studied a HDCFC, with YSZ and molten carbonate hybrid electrolyte, fuelled by pyrolysed waste medium density fibreboard (MDF), which is proven to be an excellent fuel for the HDCFC system, providing a power density as high as $390 \mathrm{~mW} \mathrm{~cm}^{-2}$ at $750^{\circ} \mathrm{C}$. Hao et. al. established HDCFCs powered by carbon sources obtained from bamboo fibre and waste paper, finding that the inherent impurities, such as calcite and kaolinite, might result in an enhanced cell performance [22]. Wood biomass char was used in a DCFC system as an alternative fuel, and a peak power density of $25 \mathrm{~mW} \mathrm{~cm}^{-2}$ at $700{ }^{\circ} \mathrm{C}$ was achieved [27]. All these experiments were conducted in DCFCs with liquid electrolyte or liquid metal. The high activation energy of carbon oxidation requires that a DCFC be operated at relatively high temperature. Any liquid at high temperature is dangerous because it may cause destructive leaking or corrosion.

There have been several reports showing the feasibility of an all-solid-state direct carbon solid oxide fuel cell (DC-SOFC), which is a SOFC directly operated on solid carbon fuel, without any feeding gas or liquid medium [28-38]. A DC-SOFC without any liquid material was first investigated by Nakagawa and Ishida in 1988 [28]. They proposed the reaction mechanism of a DC-SOFC as that: electrochemical oxidation of CO (1) occurs at the anode and 
carbon gasification reaction, known as the reversed Boudouard reaction (2), occurs on the carbon fuel:

$$
\begin{aligned}
& \mathrm{CO}+\mathrm{O}^{2-} \rightarrow \mathrm{CO}_{2}+2 \mathrm{e}^{-} \\
& \mathrm{CO}_{2}+\mathrm{C} \rightarrow 2 \mathrm{CO}
\end{aligned}
$$

This mechanism, which has been verified by Xie et. al. [29], is schematically illustrated in Fig.1. During the discharging (or operating) process, oxygen molecules at the cathode accept electrons to become oxygen anions $\mathrm{O}^{2-}$, which then diffuse through the dense, oxygen-ion-conducting electrolyte to the anode to perform reaction (1) and donate electrons to the external circuit. The $\mathrm{CO}_{2}$ would diffuse to and react with the solid carbon to produce more $\mathrm{CO}(2)$. In this way, $\mathrm{C}$ is continuously delivered from the solid carbon to the anode to maintain the electrochemical reaction for generating electricity.

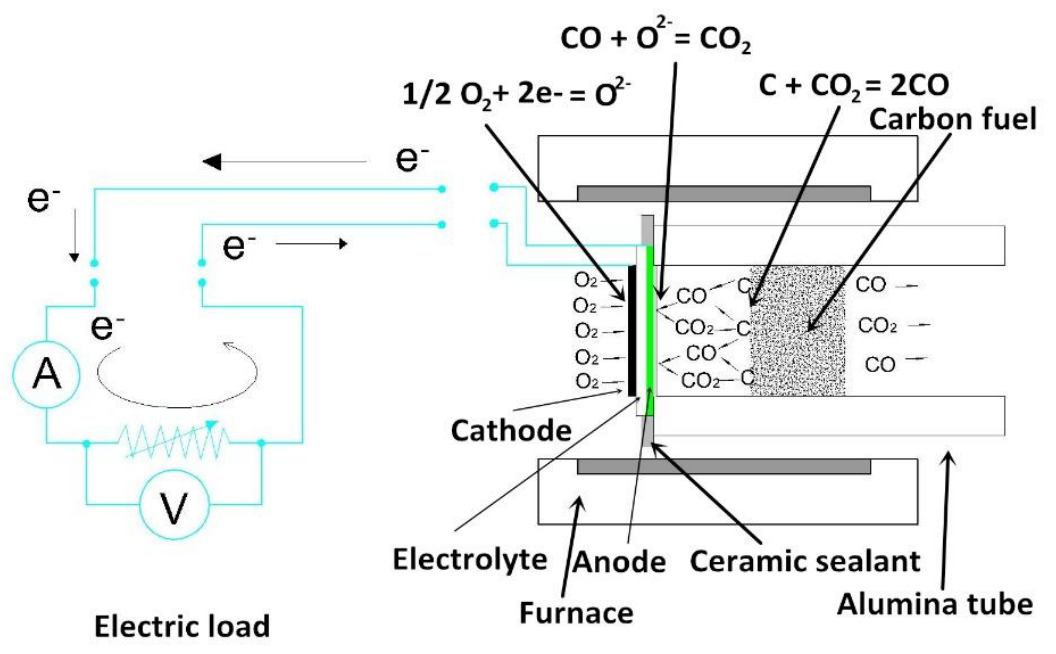

Fig. 1. Schematic illustration of the reaction mechanism of a DC-SOFC. 
Therefore, the DC-SOFC performance should be improved by catalysing both of the reactions (1) and (2). Tang et. al. investigated the performance of a DC-SOFC, with YSZ electrolyte-supported configuration, Ag-based anode, and activated carbon fuel. They applied gadolinium doped ceria (GDC, $\left.\mathrm{Gd}_{0.2} \mathrm{Ce}_{0.8} \mathrm{O}_{1.9}\right)$ on the anode to catalyse the electrochemical oxidation of carbon monoxide and $\mathrm{Fe}$ on the activated carbon fuel to catalyze the Boudourd reaction. In this way, the output performance of the DC-SOFC had been improved from a peak power density of $4 \mathrm{~mW} \mathrm{~cm}^{-2}$ to $46 \mathrm{~mW} \mathrm{~cm}^{-2}$, at $800{ }^{\circ} \mathrm{C}$ [30-32]. Later on, Bai et. al. [33] operated a Ni-YSZ anode-supported thin YSZ electrolyte SOFC stack (three-cell-in-series) with 5wt.\% Fe-loaded activated carbon fuel and got a peak power density of $465 \mathrm{~mW} \mathrm{~cm}^{-2}$ at $850^{\circ} \mathrm{C}$. With a total effective area of $5.4 \mathrm{~cm}^{2}$, the stack gave an open circuit voltage of $3 \mathrm{~V}$ and a peak power of $2.4 \mathrm{~W}$. A processed brown coal with inherent inorganic species, namely $\mathrm{Fe}$, $\mathrm{Ca}$ and $\mathrm{Mg}$, was applied to fuel a DC-SOFC, which achieved a superior power density of $89 \mathrm{~mW} \mathrm{~cm}^{-2}$ at $800{ }^{\circ} \mathrm{C}$, comparing to that fuelled with acid washed coal $\left(65 \mathrm{~mW} \mathrm{~cm}^{-2}\right)$ [34]. Similarly, an industrial coal char with Boudouard reaction catalyst $\left(\mathrm{Fe}_{\mathrm{m}} \mathrm{O}_{\mathrm{n}}, \mathrm{CaO}\right.$, etc.) was used as a fuel source for an anode-supported DC-SOFC, and a peak power density $204 \mathrm{~mW} \mathrm{~cm}^{-2}$ at $850^{\circ} \mathrm{C}$ was obtained [35]. Apparently, the Boudouard reaction catalyst plays an extremely important role in DC-SOFC operation.

It is noteworthy that this kind of all-solid-state DC-SOFCs can be very simple in configuration because they need neither feeding gas equipment nor 
high temperature liquid management, and the cost of DC-SOFC system could be reduced significantly compared to other SOFCs. Besides, it is not necessary for the carbon fuel to have a chemical, even physical, contact with the anode. This may enable the design of DC-SOFC systems to be quite flexible.

In this paper, we report our research on DC-SOFCs operated on biochar derived from orchid leaf, which is very abundant in the area of south China. The biochar has a natural porous structure, and more important, with natural calcium catalyst distributed in an optimal pattern, which is very beneficial for the DC-SOFC reaction. DC-SOFCs with the orchid leaf biochar as fuel are tested and compared to those operated with Fe-loaded activated carbon. The microstructure and composition of the leaf biochar are analysed in details.

\section{Experiment}

\subsection{Pre-treatment of carbon fuels}

Leaf char. Some fallen leaves from orchid trees (Fig.2a) were cleaned and heated in $\mathrm{N}_{2}$ atmosphere within a furnace with a temperature raising rate of 5 ${ }^{\circ} \mathrm{C} \min ^{-1}$ and dwelling at $700{ }^{\circ} \mathrm{C}$ for $1 \mathrm{~h}$. Then, the system was cooled down to room temperature. The obtained leaf char (Fig.2b) was subsequently ground in an agate mortar, and then sieved through a 77 mesh sieve to control the particle size (Fig.2c). 
Fe-loaded activated carbon. Activated carbon granules (Activated Charcoal, 8-16 mesh, Aladdin, China) were crushed with an electric grinder and then sieved with a 77 mesh sieve. Fe catalyst was loaded on the carbon by the conventional infiltration technique [32, 33]. First, $\mathrm{Fe}\left(\mathrm{NO}_{3}\right)_{3} \cdot 9 \mathrm{H}_{2} \mathrm{O}$ (A.R., Guangzhou Chemical Reagent Factory, China) was dissolved in deionized

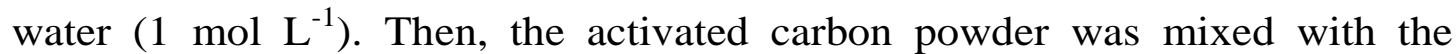
$\mathrm{Fe}\left(\mathrm{NO}_{3}\right)_{3}$ solution under stirring for $1 \mathrm{~h}$ and let stand for $12 \mathrm{~h}$. Then the mixture was heated at $80{ }^{\circ} \mathrm{C}$ to evaporate the water. Finally, the residue was heated at $700{ }^{\circ} \mathrm{C}$ for $60 \mathrm{~min}$ under flowing $\mathrm{N}_{2}$ to decompose the nitrate. The mass ratio of C: Fe was 95:5.

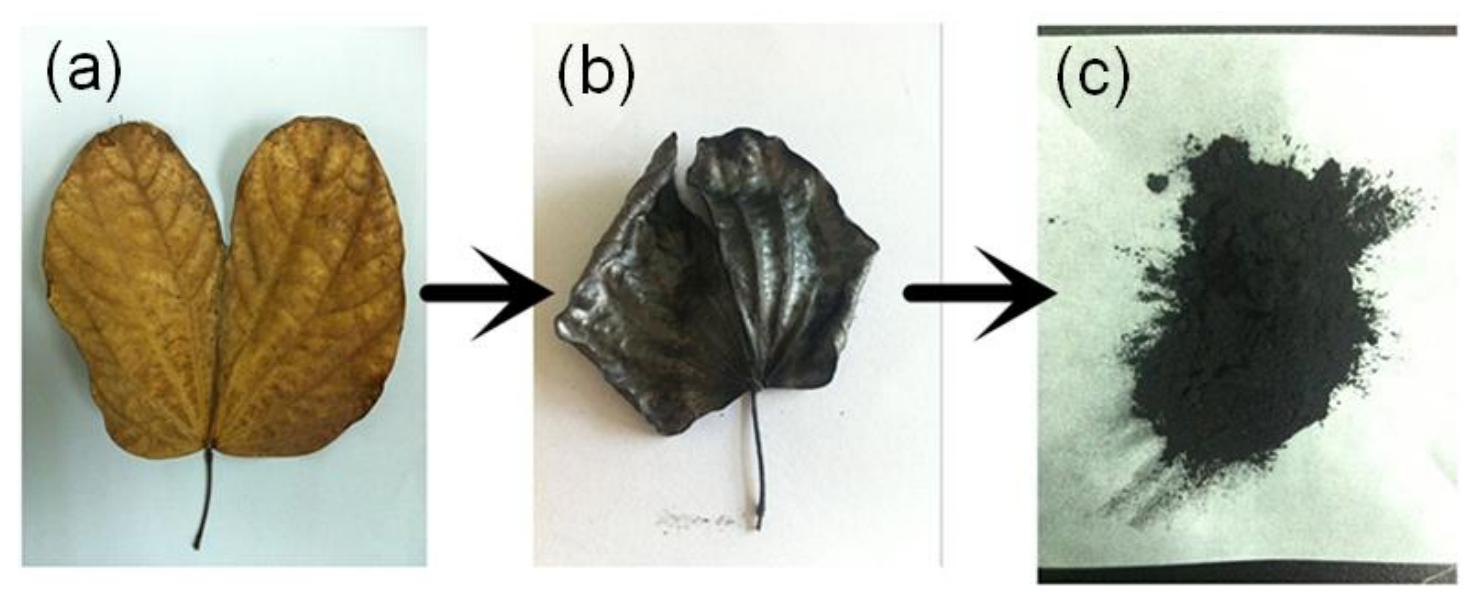

Fig. 2. Morphology change of the leaf biochar during the pre-treatment process.

Simulated leaf char. According to the TG result (as will be described later on) of leaf char, a simulated leaf char was made by mixing $40 \mathrm{wt} . \%$ catalyst of carbon gasification and $60 \mathrm{wt} . \%$ activated carbon. The catalyst was comprised of $\mathrm{CaCO}_{3}$ (90.5 wt. \%, A.R., Chengdu Jinshan chemical reagent Co., China), 
$\mathrm{K}_{2} \mathrm{CO}_{3}$ (6.5 wt. \%, A.R., Tianjin Kemiou Chemical Reagent Co., China) and MgO (3.0 wt. \%, A.R., Tianjin Kemiou Chemical Reagent Co., China).

\subsection{Fabrication of SOFCs}

Yttria-stabilized-zirconia (YSZ, TZ-8Y, Tosoh Corporation, Tokyo, Japan), with 1 wt. $\% \mathrm{Al}_{2} \mathrm{O}_{3}$ addition to improve the performance, was used as the electrolyte material $[39,40] .20 \mathrm{~g}$ YSZ powder and $0.2 \mathrm{~g}$ alumina powder $\left(\mathrm{Al}_{2} \mathrm{O}_{3}\right.$, Xinfumeng, China, $\alpha$-phase, $99.99 \%$ purity) were mixed by ball-milling for $3 \mathrm{~h}$ with proper amounts of alcohol as solvent. After ball-milling, the mixture was dried under an infrared lamp to evaporate the solvent. Then, $5 \mathrm{~mL}$ polyvinyl butyral (PVB) ethanol solution (PVB concentration: 6 wt \%) was added into the dry powder drop by drop under grinding. Afterward, the $\mathrm{Al}_{2} \mathrm{O}_{3}$-added-YSZ powder was pressed into pellets (each of $0.6 \mathrm{~g}$ in weight and $20 \mathrm{~mm}$ in diameter), followed by sintering at 1400 ${ }^{\circ} \mathrm{C}$ for $4 \mathrm{~h}$. The dense electrolyte pellets had a typical thickness of $0.5 \mathrm{~mm}$, with a diameter of $16 \mathrm{~mm}$.

Cermets consisting of silver and gadolinium doped ceria (GDC) were used as the material for both anode and cathode [32, 37]. GDC powder $\left(\mathrm{Gd}_{0.1} \mathrm{Ce}_{0.9} \mathrm{O}_{2-\delta}\right.$, purity $\geq 99.5 \%$, particle size $(\mathrm{d} 50): 0.5-3 \mu \mathrm{m}$, Ningbo Institute of Materials Technology \& Engineering, China), silver paste (DAD-87, with 70 wt.\% Ag, Shanghai Research Institute of Synthetic Resins, Shanghai, China) and PVB Alpha-Terpineol solution (concentration: 10wt \%) with a weight ratio 
of 3:10:3 were mixed by grinding in an agate mortar for $3 \mathrm{~h}$ until the slurry was uniform. The as-prepared slurry was painted on both sides of each YSZ disks, followed by drying at $140^{\circ} \mathrm{Cin}$ an oven and then sintering at $880{ }^{\circ} \mathrm{C}$ for $4 \mathrm{~h}$. The cathode area (effective area) of all the cells was controlled to be the same, 0.9 $\mathrm{cm}^{2}$.

\subsection{SOFC assembly and testing}

Each of the disk cells was attached to one end of an alumina tube with silver paste and ceramic adhesives (High temperature ceramic adhesives \& pastes, P/N 552, Aremco Products, INC. USA) as sealing and jointing materials (Fig.1). The outer diameter of the alumina tube was about $16 \mathrm{~mm}$, which was just fit for a single cell. For the cells tested with humidified hydrogen as fuel, the fuel gas was fed into the anode of the cell through a thin ceramic tube. The

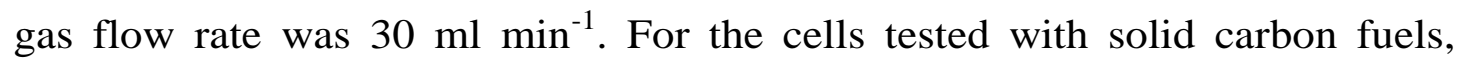
including the leaf char, the Fe-loaded activated carbon, and the simulated leaf char, $0.5 \mathrm{~g}$ solid fuel was filled into the anode chamber of each cell. Some ceramic cotton was stuffed into the ceramic tube, next to the carbon fuel to prevent it from flowing. A rubber stopper with a plastic gas leading pipe was applied to block the open end of the alumina tube. Some Teflon tape and vacuum sealing resin were coated on the crevice between ceramic tube and rubber stopper to avoid gas leaking. For all the cells tested, the ambient air was used as the oxidant. 
The electrochemical performances of the SOFCs were characterized using Iviumstat electrochemical analyser (Ivium Technologies B.V., Netherlands). The operating temperature was $850{ }^{\circ} \mathrm{C}$. X-ray diffraction (XRD, Rigaku D/max-IIIA diffratometer, Japan, $\mathrm{Cu}-\mathrm{Ka}$ radiation, operated at $35 \mathrm{kV}, 30 \mathrm{~mA}, 1$ $=1.54184 \AA$ ) was performed on the leaf char fuel before and after discharging process. The microstructure of SOFCs and leaf biochar was characterized with field emission scanning electron microscope (SEM, Carl Zeiss AG-Merlin, Germany). The thermal decomposition of leaf char in terms of weight loss was carried out using a Thermogravimetric analyser (TGA/ DSC 1, Mettler Toledo, Switzerland) in a flowing oxygen atmosphere with a flow rate of $30 \mathrm{ml} \mathrm{min}^{-1}$ and a heating rate of $10{ }^{\circ} \mathrm{C} \mathrm{min}^{-1}$ from room temperature to $1000{ }^{\circ} \mathrm{C}$.

\section{Results and discussion}

\subsection{Characteristics of the as-prepared SOFCs}



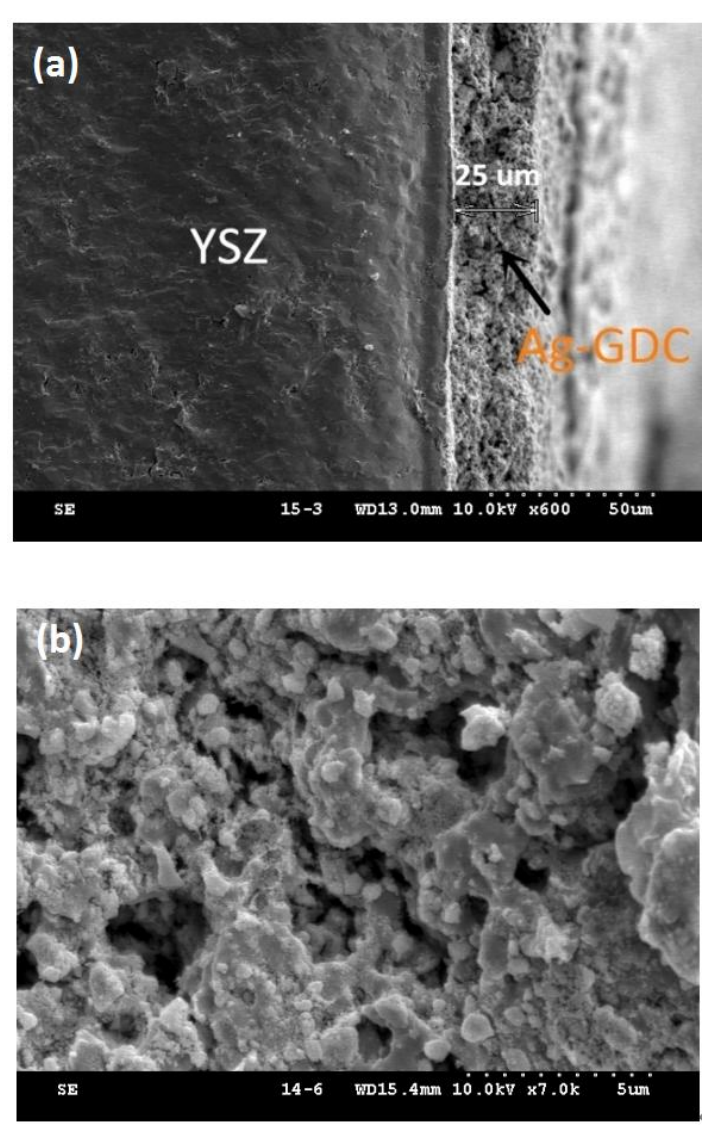

Fig. 3. SEM pictures of cross section (a) and anode (b) of an as- prepared SOFC.

The microstructures of the as prepared SOFCs are shown in Fig.3. It can be seen from the section image (Fig.3a) that the YSZ electrolyte is quiet dense, only with some closed pores which will not affect the gastight of the cell. The anode layer, with a thickness of $25 \mathrm{um}$, closely attaches to the YSZ electrolyte substrate. The surface image of the anode (Fig.3b) shows the anode is fairly porous with relatively uniform microstructure. 
(a)

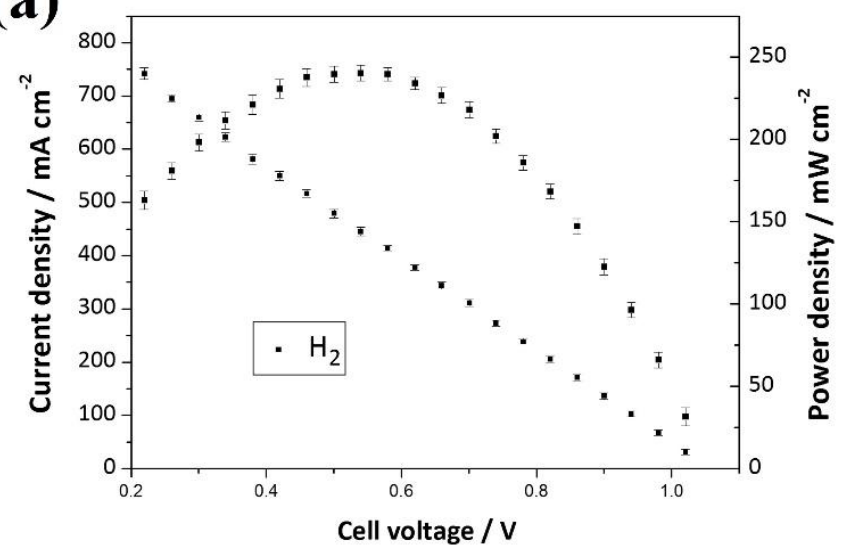

(b)

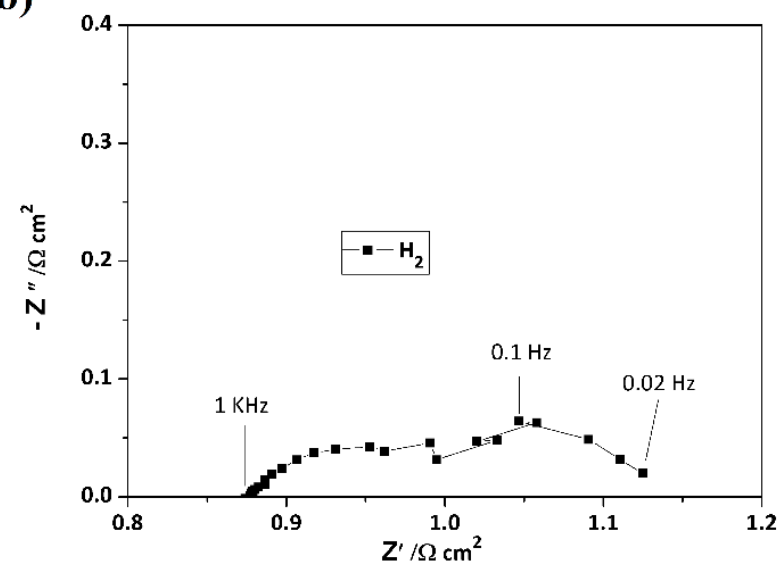

Fig. 4. Cell performance plot with error bars (a) and impedance spectra (b) of the as-prepared SOFC powered by hydrogen at $850^{\circ} \mathrm{C}$.

Fig.4 shows the output performance with error bars and impedance spectra of a typical as-prepared SOFC operated at $850{ }^{\circ} \mathrm{C}$, with humidified $\mathrm{H}_{2}$ (3 vol.\% $\left.\mathrm{H}_{2} \mathrm{O}\right)$ as fuel. An open circuit voltage of $1.05 \mathrm{~V}$ and a maximum power density of $240 \mathrm{~mW} \mathrm{~cm}^{-2}$ are achieved, as shown in Fig.4 (a), indicating that the SOFCs are well prepared.

The errors are calculated through the standard deviation of the data. In the experiment, we controlled the voltages and measured the corresponding 
currents. Hence the voltages are represented in $\mathrm{X}$-axis and currents $\mathrm{Y}$-axis in Fig.4 (a). As we can see, the performance errors of the hydrogen cells are very small, indicating the quality of the as-prepared cells is reliable.

For the impedance spectrum shown in Fig.4 (b), the intercept of the real axis at high-frequency, which corresponds to the cell ohmic resistance, is about $0.88 \Omega \mathrm{cm}^{2}$, while the intercepts at low-frequency, which corresponds to the overall cell resistance, is about $1.12 \Omega \mathrm{cm}^{2}$. The high ohmic resistance is reasonable because the YSZ electrolyte is relatively thick (500 um). The polarization resistance of the cell is the difference between the overall resistance and the ohmic resistance, which is $0.24 \Omega \mathrm{cm}^{2}$.

\subsection{Electrochemical performance of DC-SOFCs}

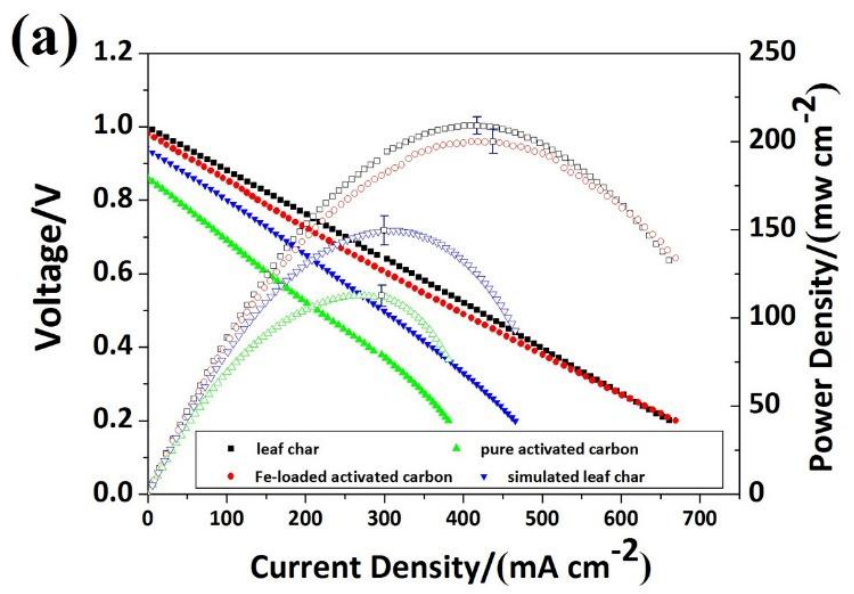


(b)

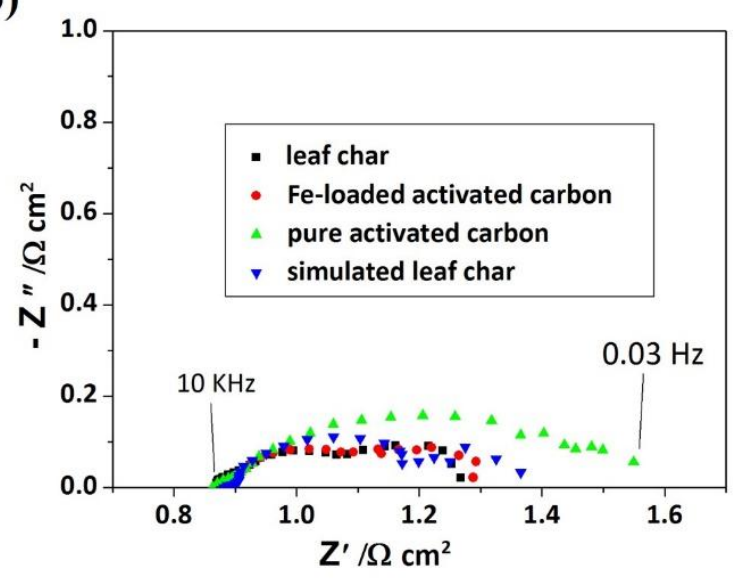

Fig. 5. Electrochemical characteristics of DC-SOFCs fuelled by leaf char,

Fe-loaded activated carbon, pure activated carbon, and simulated leaf char, respectively, at $850^{\circ} \mathrm{C}$. (a) Output performances (with representative error bars); (b) AC impedance spectra.

To investigate the output performances of the cells operated with different carbon fuels, we tested four cells at $850^{\circ} \mathrm{C}$ and obtained four sets of data for each kind of fuels: leaf char, Fe-loaded activated carbon, pure activated carbon, and simulated leaf char. From the four sets of data corresponding to each kind of fuels, we selected the one, with the maximum power density closest to the average value, to plot the $I-V$ and $I-P$ curves, as shown in Fig.5 (a). Similar to the method we used for the hydrogen cell, standard deviations are calculated. The representative error bars showing the deviations of the maximum power densities are included in Fig. 5(a). The relatively high temperature of $850^{\circ} \mathrm{C}$ is chosen as the operating temperature, because $\mathrm{CO}$ is favoured at high temperature in a C-O system that contains excess amount of carbon [29]. 
It has been demonstrated that the performance of a DC-SOFC operated on activated carbon can be significantly improved by loading some Fe catalyst on the carbon fuel $[32,33]$, which is consistent with the results shown in Fig.5 (a). So far, the best reported DC-SOFC performance has been obtained from $5 \mathrm{wt} . \%$ Fe-loaded activated carbon fuel [33]. As can be seen from Fig.5 (a), the leaf char DC-SOFC gives a maximum power density of $212 \mathrm{~mW} \mathrm{~cm}^{-2}$, which is even slightly higher than that operated on Fe-loaded activated carbon $(201 \mathrm{~mW}$ $\mathrm{cm}^{-2}$ ). The open circuit voltages of the two cells are almost the same, about 1.0 V. Fig.5 (b) reveals the electrochemical impedance spectra of the DC-SOFCs measured under open circuit voltage. The ohmic resistances of all the cells are almost the same $\left(0.88 \Omega \mathrm{cm}^{2}\right)$ due to the identical SOFC configuration and operating temperature. However, the polarization resistances of the cells are different, with the lowest associated with the leaf char DC-SOFC and the highest with the pure activated carbon one. It is reasonable that the DC-SOFC operated on the activated carbon without any catalyst gives the largest polarization resistance, because the Boudouard reaction (2) rate might be too slow to provide sufficient $\mathrm{CO}$ for the electrochemical reaction (1), which also results in lower OCV. The better performance and lower polarization resistance of the leaf char DC-SOFC than those of the DC-SOFC operated with Fe-loaded activated carbon suggests that the Boudouard reaction within the leaf char DC-SOFC is better catalysed than that within the others. 


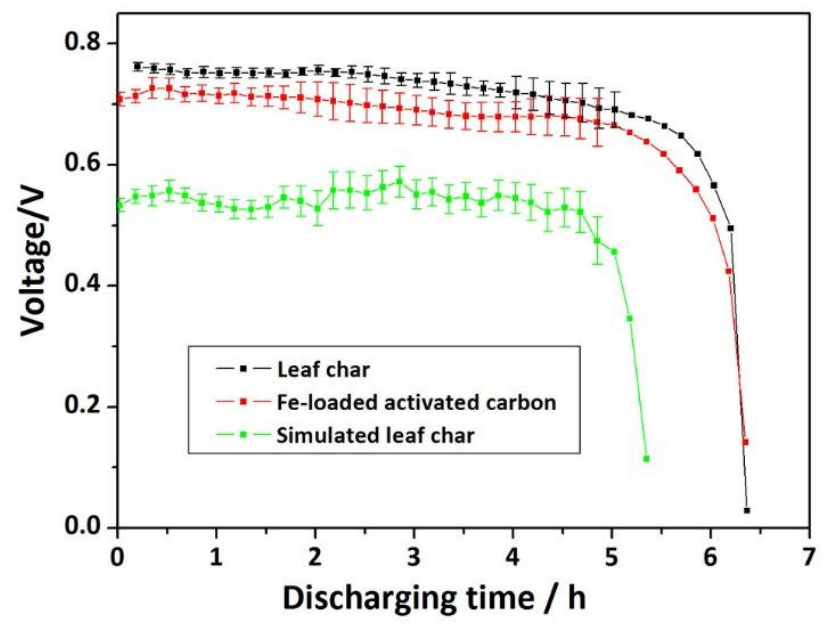

Fig. 6. The discharging curves, with error bars, of DC-SOFCs respectively with $0.5 \mathrm{~g}$ leaf char, Fe-loaded activated carbon and simulated leaf char as fuel, operated at constant current of $0.2 \mathrm{~A}\left(0.22 \mathrm{~A} \mathrm{~cm}^{-2}\right)$, at $850{ }^{\circ} \mathrm{C}$.

Shown in Fig. 6 are the discharging curves, with error bars, of the DC-SOFCs, respectively operated with $0.5 \mathrm{~g}$ leaf char and 5 wt.\% Fe-loaded activated carbon as fuel, operated at $850^{\circ} \mathrm{C}$, maintained at a constant current of $0.20 \mathrm{~A}\left(0.22 \mathrm{~A} \mathrm{~cm}^{-2}\right)$. Powered by the same quality of carbon fuel, the cells reveal different discharging voltage and discharging time. The discharging time of the cell, either with the fuel of leaf char or with the Fe-loaded activated carbon, is about $7.0 \mathrm{~h}$, with the discharging plateau of the leaf char (over $0.7 \mathrm{~V}$ ) DC-SOFC higher than that of the Fe-loaded carbon one. Even considering the experimental errors, the performance of the SOFC operated with the leaf char as fuel is a little superior to that with the Fe-loaded activated carbon. 
All the above evidences show that the leaf char is a good DC-SOFC fuel. It is even better than the best reported Fe-loaded activated carbon. To figure out why the leaf char shows such a good performance as the fuel of DC-SOFCs, the leaf char is subsequently characterized by Raman spectroscopy, X-ray diffraction, scanning electron microscope, energy dispersive X-ray spectroscopy, and thermogravimetric analysis.

\subsection{Microstructure and composition of leaf char}

Fig. 7(a) shows the SEM image of the leaf char. As a comparison, the image of the activated carbon is shown in Fig. 7(b). It can be seen that both kinds of carbon have large pores with an average size around $10 \mu \mathrm{m}$. The thickness of the wall between the adjacent pores for the leaf char is thinner than that for the activated carbon. However, it is not likely the superior performance of the leaf char over the activated carbon is caused by the microstructure because the reactions occurs on the surface while BET experiment shows that the specific surface of the activated carbon $\left(496 \mathrm{~m}^{2} \mathrm{~g}^{-1}\right)$ is larger than that of the leaf char $\left(56 \mathrm{~m}^{2} \mathrm{~g}^{-1}\right)$. 

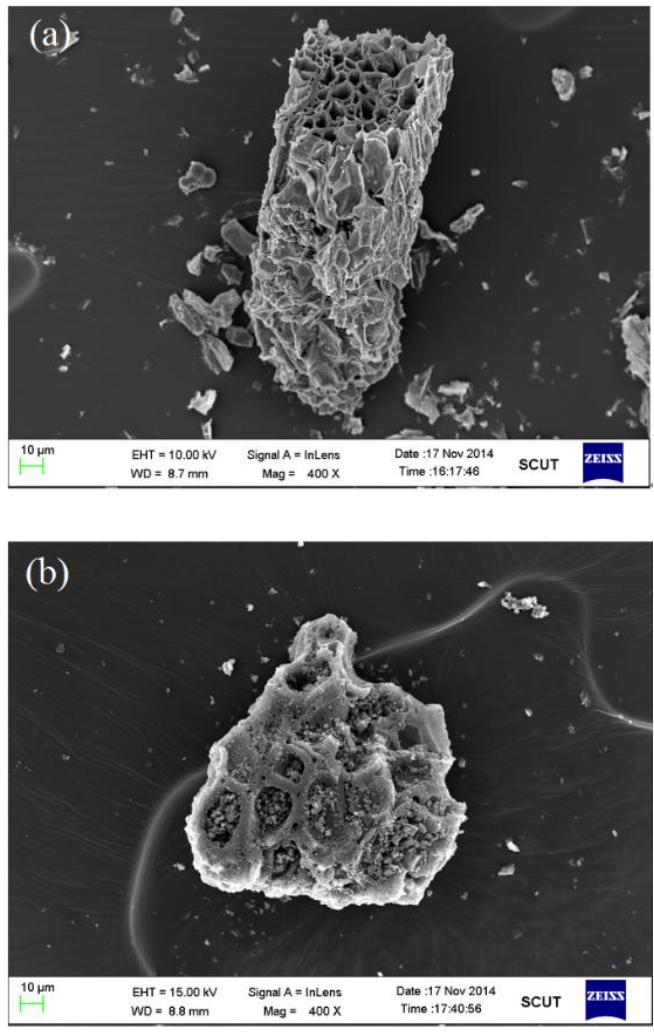

Fig. 7. SEM micrographs showing the porous structure of leaf char (a) and activated carbon (b).

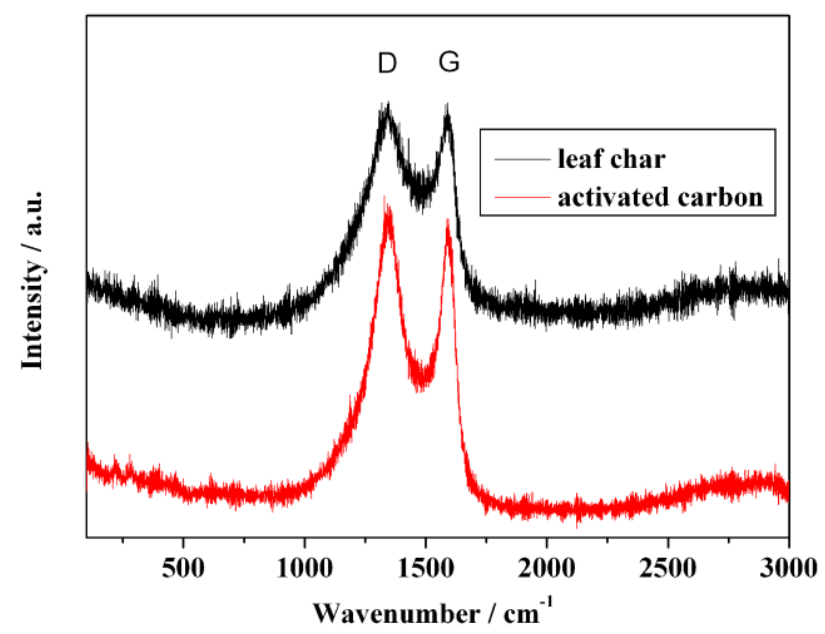

Fig. 8. The Raman spectra of leaf char and activated carbon. 
It is well known that carbon exists in several forms among which graphite is the most ordered and it is inert to chemical reactions. The Raman spectra of leaf char and activated carbon are shown in Fig. 8. Both of them have two prominent peaks at 1340 and $1598 \mathrm{~cm}^{-1}$, corresponding to the $\mathrm{D}$ and $\mathrm{G}$ bands of carbon, respectively. Generally, in a Raman spectrum, D band corresponds to disordered carbon while $\mathrm{G}$ band represents the in-plane bond-stretching motion of the pairs of $\mathrm{C} \mathrm{sp}{ }^{2}$ atoms of graphite, representing ordered structure. The peak intensity ratios of the $\mathrm{D}$ to $\mathrm{G}$ band $\left(I_{D} / I_{G}\right)$ of both carbons are very close, over $50 \%$. Generally, the disordered carbon is more active than graphite for reactions. Obviously, the portion of disordered carbon in the leaf char is similar to that in the activated carbon. Therefore, the superior performance of the leaf char is not caused by the carbon forms present.

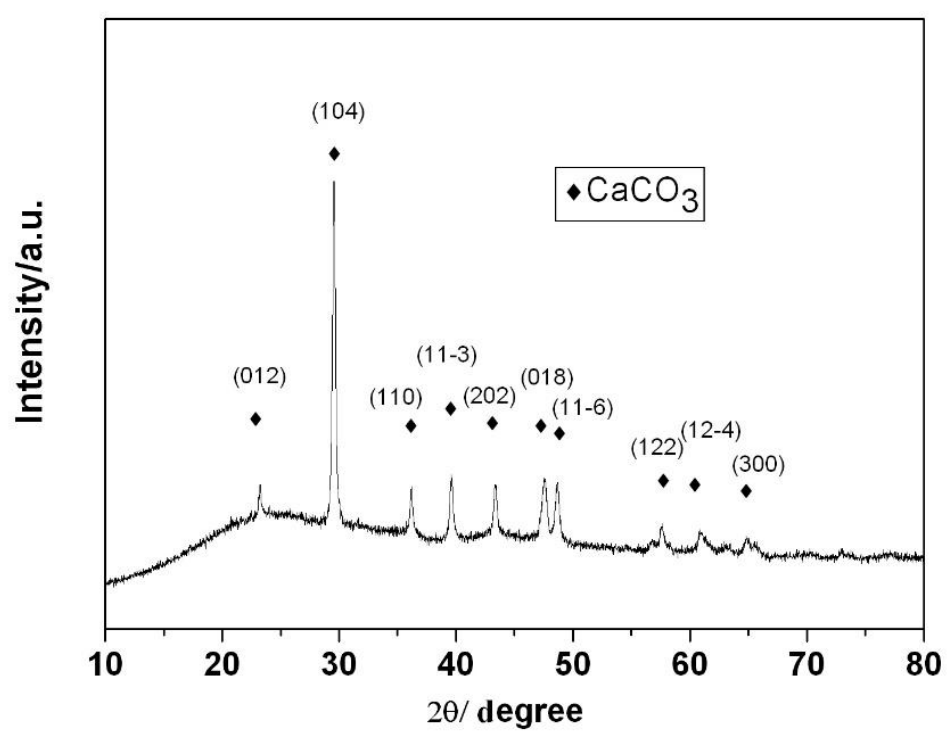

Fig. 9. X-ray diffraction spectra for leaf char. 
X-ray diffraction is measured to determine the composition of the leaf char. As can be seen from Fig. 9, there is a hexagonal system of calcite, indicating that $\mathrm{CaCO}_{3}$ is one of the main components of the leaf char. A weak broaden peak around $2 \theta=24^{\circ}$ is observed in the XRD pattern, which corresponds to graphite crystal, further confirming disorder structure of the carbon, which is consistent with the Raman spectrum.

In fact, alkali metal and alkaline earth metal are excellent catalysts for the Boudouard reaction. Risnes et.al. [41] have found that calcium is a potential catalyst for promoting the carbon gasification reaction and shows low agglomeration tendency and volatilization, comparing to that of $\mathrm{K}$ and $\mathrm{Na}$. Similar experiments were also performed by Quyn et.al. [42]. The Ca in the leaf char should be the cause of the high performance of the corresponding DC-SOFC.

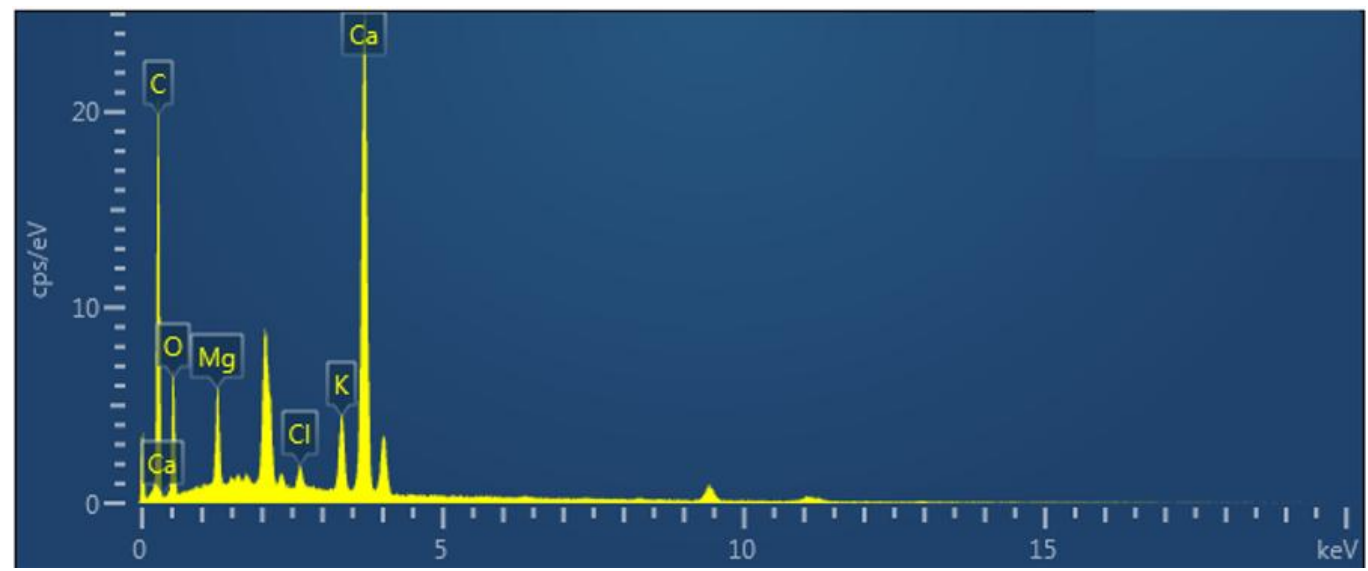

Fig. 10. Element distribution diagram for leaf char.

Considering some trace amount of elements, which cannot be detected by XRD, may also play an important role in catalysing reactions, the leaf char is 
examined by EDX. The result is shown in Fig.10. As can be seen, apart from $\mathrm{Ca}$, some $\mathrm{K}$ and $\mathrm{Mg}$ also exist in the leaf char.

To estimate the amount of the metal compounds in the leaf char, TG/DSC measurement is carried out for the leaf char from room temperature to $1000{ }^{\circ} \mathrm{C}$ under oxygen atmosphere. The result is shown in Fig. 11.

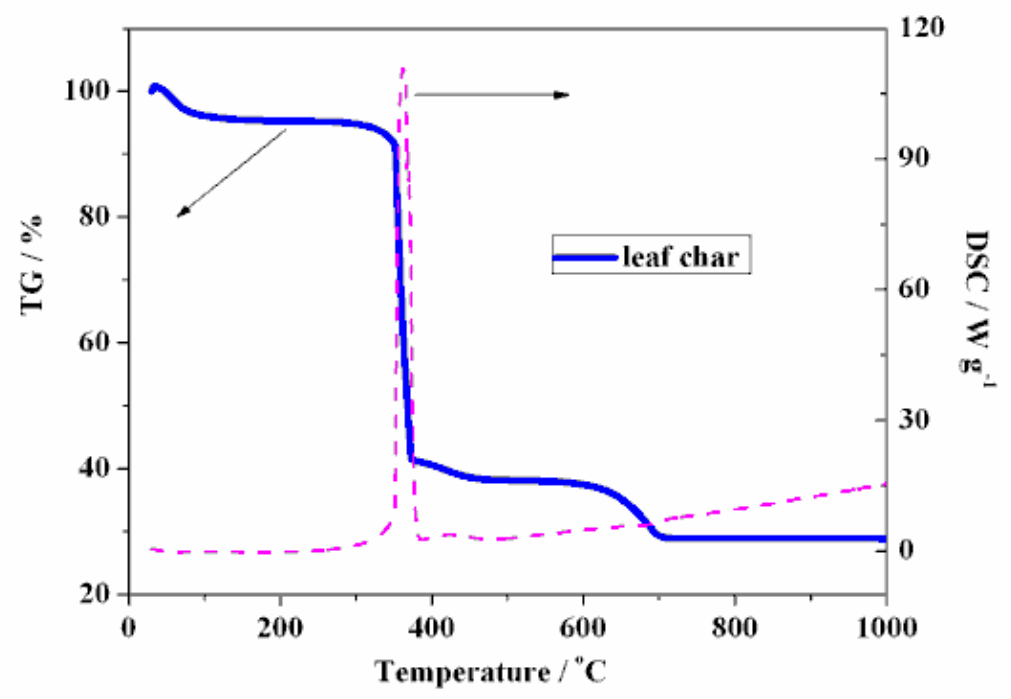

Fig. 11. Thermogravimetric and differential thermal curves of the leaf char.

There is a slight weight loss under $100{ }^{\circ} \mathrm{C}$, resulted from the vaporization of free water and other volatile organics. A rapid weight loss can be observed at about $358^{\circ} \mathrm{C}$, which corresponds to the oxidation of carbon, along with a sharp peak in the differential thermal curve, indicating large quantity of heat releasing. With further temperature increases, the leaf char slowly loses its weight from $40 \%$ to about $12 \%$ during the temperature increasing from $400{ }^{\circ} \mathrm{C}$ to $700{ }^{\circ} \mathrm{C}$. This weight loss may be mainly caused by the decomposition and volatilization 
of inorganic salts, such as $\mathrm{CaCO}_{3}$, which account for about $40 \%$ of the leaf char.

After discharging test, majority of $\mathrm{C}$ exists in leaf char is consumed through electrochemical reaction, therefore the remainder after discharging test is mainly mineral salt. It is examined by EDX and the results are listed in Table.1. From Table 1, we can see that the components of the mineral salt are Ca of 36.3 wt. $\%, \mathrm{Mg}$ of 1.1 wt. $\%$ and $\mathrm{K}$ of 2.2 wt. \%. Therefore, Ca element is the main component of the mineral salt. Furthermore, the weight ratio of $\mathrm{Ca}, \mathrm{C}$ and $\mathrm{O}$ is consistent with that of $\mathrm{CaCO}_{3}(\mathrm{Ca}: \mathrm{C}: 3 \mathrm{O}=36.32: 12.99: 47.4 \approx 40: 12$ : 48), implying that the remainder of leaf char is mainly $\mathrm{CaCO}_{3}$, which is confirmed by the result of XRD.

\section{Table 1}

The components of leaf char after discharging test.

\begin{tabular}{llllll}
\hline Element & $\mathrm{C}$ & $\mathrm{O}$ & $\mathrm{Mg}$ & $\mathrm{K}$ & $\mathrm{Ca}$ \\
\hline Wt $\%$ & 12.99 & 47.4 & 1.07 & 2.22 & 36.32 \\
At $\%$ & 21.4 & 58.6 & 0.9 & 1.1 & 18 \\
\hline
\end{tabular}

3.4. Comparison of DC-SOFCs with natural leaf char and artificially simulated one.

To verify the effects of the components of the leaf char on the performance of DC-SOFCs, a carbon fuel was made by simulating the composition of the natural leaf char. It was made by mechanically mixing $40 \mathrm{wt} \%$ catalyst and 60 wt. \% activated carbon, according to the TG result of leaf char. The catalyst was comprised of $\mathrm{CaCO}_{3}$ (90.5 wt. \%), $\mathrm{K}_{2} \mathrm{CO}_{3}(6.5$ wt. \%) and $\mathrm{MgO}(3.0$ 
wt. \%), according to the component of mineral salt of leaf char, as listed in Table 1.

Fig.5 (a) shows that the performance of the DC-SOFC with simulated leaf char is higher than that of the DC-SOFC with pure activated carbon, verifying the catalytic effects of the alkaline and alkaline earth metals. However, the open circuit voltage of the DC-SOFC with simulated leaf char $(0.93 \mathrm{~V})$ is lower than that with the natural leaf char $(1.0 \mathrm{~V})$. Meanwhile, the output performance of a DC-SOFC with leaf char is much higher than that of the cell with simulated leaf char (152 $\left.\mathrm{mW} \mathrm{cm}^{-2}\right)$. The corresponding electrochemical impedance spectroscopy results are illustrated in Fig.5 (b). The ohmic resistances of the two cells are identical $\left(0.88 \Omega \mathrm{cm}^{2}\right)$, while the polarization resistance of natural leaf char is obviously smaller than that of simulated one, suggesting that mechanically mixing carbonate catalysts and activated carbon cannot effectively promote the Boudouard reaction or decrease the polarization resistance of the DC-SOFC.

Comparing the discharging curves of the two cells respectively with natural leaf char and simulated leaf char (Fig. 6), the discharging platform of the former, with better output performance, is obviously higher than the latter. Previous research shows that only when $\mathrm{Ca}$ is well dispersed to active sites of carbon can notable catalytic activity be achieved [43, 44]. Fig. 12 shows a schematic illustration of the catalyst distribution in a leaf char (a) and in an artificial catalyst-loaded carbon (b). Benefit from the natural even-distributed 
catalyst in the leaf char, the DC-SOFC with natural leaf char has a high cell performance because of the sufficient contacts, in atomic or molecular level, between carbon and catalyst. While in the DC-SOFC with simulated leaf char, with inattentive contact to carbon, it is difficult for $\mathrm{CaCO}_{3}$ to effectively catalyse the Boudouard reaction.
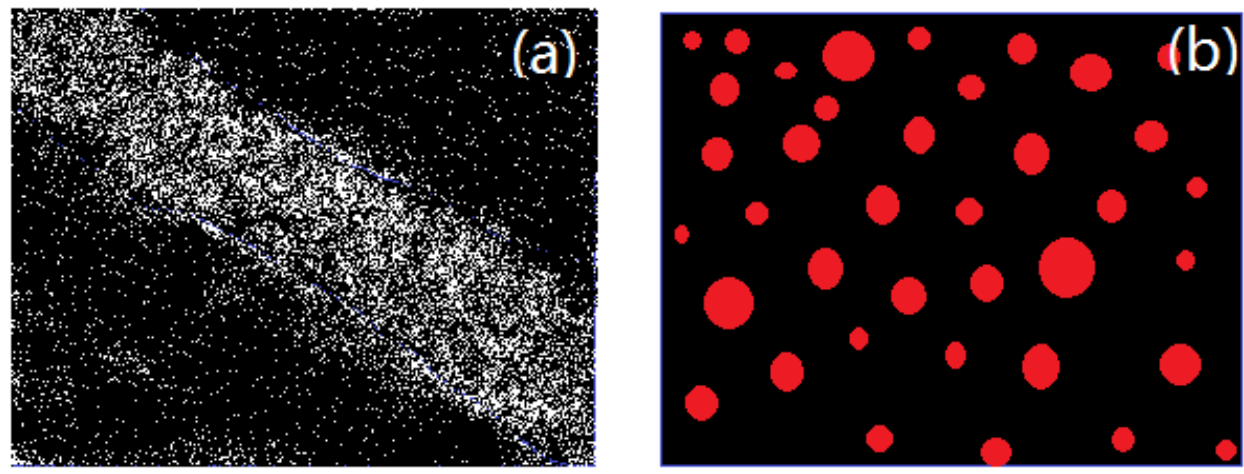

Fig. 12. Schematic illustration of catalyst distribution in leaf-char (a) and artificial catalyst-loaded carbon (b), respectively. (Black colour represents carbon, white represents natural $\mathrm{Ca}$, and red represents artificial catalyst.)

Fig. 13 is the EDX surface scanning element distribution mapping pictures of the leaf char. As we can see, $\mathrm{C}, \mathrm{O}, \mathrm{K}$, and $\mathrm{Mg}$ are evenly distributed on the surface of leaf char, while $\mathrm{Ca}$ mainly exists in the leaf vein. The brighter part of the illustration shown in Fig.12 (a) can be taken as the $\mathrm{Ca}$ distribution in leaf vein. It is understandable by comparing Fig.12 (a) and (b), that even the catalyst concentration varies, the catalyst distribution of the natural leaf char is more homogeneous that that of an artificial catalyst-loaded carbon. As alkaline metal and alkaline earth metal are good catalyst for Boudouard reaction [45-48], $\mathrm{Ca}, \mathrm{Mg}$ and $\mathrm{K}$ might play an important role in catalysing carbon gasification reaction to improve the cell's output 
performance. The alkaline or alkaline earth metals may exist in the form of metal oxide or metal carbonate, according to the partial pressure of oxygen and $\mathrm{CO}_{2}$ atmosphere around the leaf char in a DC-SOFC. According to the chemical equilibrium theory of thermodynamics, $\mathrm{Ca}$ exists mainly in the form of $\mathrm{CaO}$ in a DC-SOFC operated at $850{ }^{\circ} \mathrm{C}$, which has been demonstrated by XRD measurement.

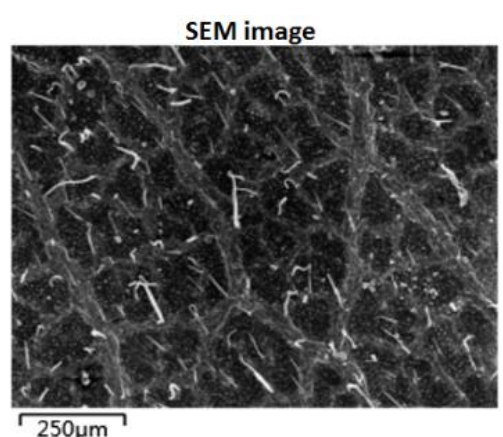

$$
\longdiv { 2 5 0 \mu \mathrm { m } }
$$

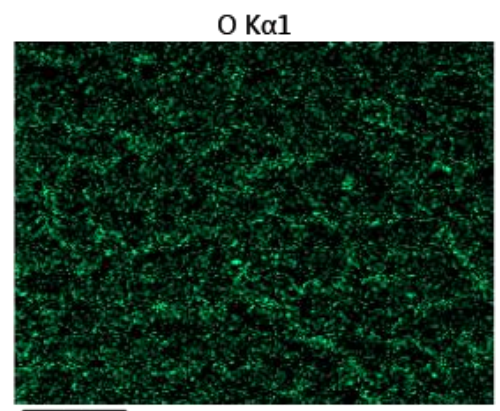

$$
\sqrt{250 \mu \mathrm{m}}
$$

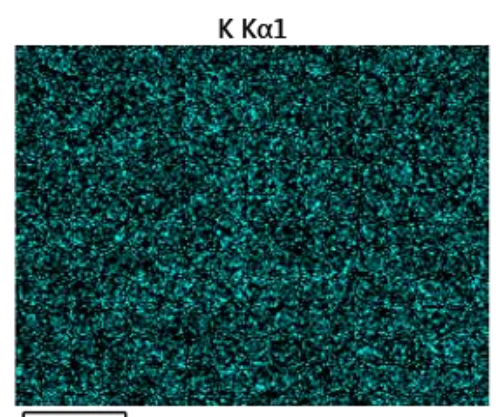

$\longdiv { 2 5 0 \mu \mathrm { m } }$
C K $\alpha 12$

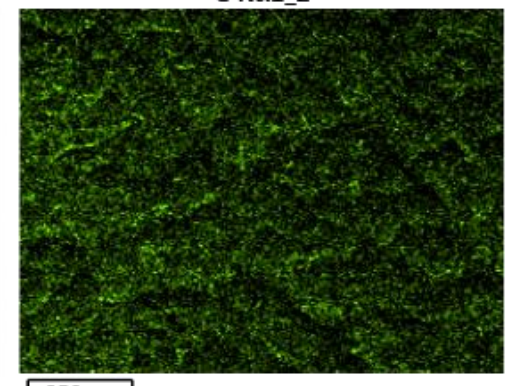

$250 \mu \mathrm{m}$

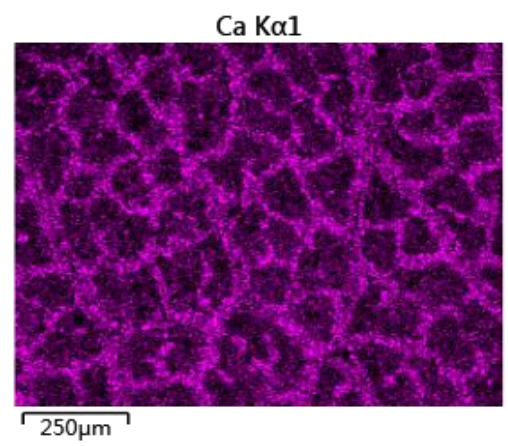

$\mathrm{Mg} \mathrm{K \alpha} 12$

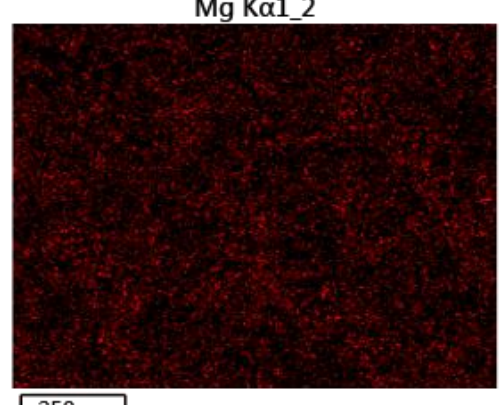

$\longdiv { 2 5 0 \mu \mathrm { m } }$

Fig. 13. EDX surface scanning element distribution mapping pictures of the leaf char. 


\section{Conclusions}

A direct carbon solid oxide fuel cell (DC-SOFC) can be operated on biochar derived from orchid tree leaves. The DC-SOFC is all-solid-state, without any feeding gas for reforming reaction or liquid medium for carbon delivering. The maximum power density of the DC-SOFC operated on the orchid tree leaf char was $212 \mathrm{~mW} \mathrm{~cm}^{-2}$, at $850^{\circ} \mathrm{C}$, even slightly higher than that operated on the best reported 5 wt. \% Fe-loaded activated carbon, $201 \mathrm{~mW}$ $\mathrm{cm}^{-2}$. Raman spectra and SEM characterization showed that the microstructure and carbon form of the leaf char were similar to the situation of activated carbon. XRD, TG-DTA and EDX analysis indicated that there was large amount of $\mathrm{CaCO}_{3}$ ( 40 wt. \%), along with some trace amount of $\mathrm{K}$ and $\mathrm{Mg}$ in the leaf char. These alkaline earth and alkaline metal elements, existing in the form of carbonates or oxides, played a key role in catalysing the Bououard reaction to enhance the performance of the corresponding DC-SOFCs. A DC-SOFC was operated with a carbon fuel prepared by simulating the composition of the natural leaf char. Its performance was significantly lower than the one with natural leaf char, confirming the importance and superior of uniform distribution of catalyst in the natural leaf char. A DC-SOFC operating on $0.5 \mathrm{~g}$ leaf char at $850^{\circ} \mathrm{C}$, discharging at a constant current of $0.2 \mathrm{~A}(0.22 \mathrm{~A}$ $\mathrm{cm}^{-2}$ ), gave a discharging plateau of over $0.7 \mathrm{~V}$ lasting for about $6 \mathrm{~h}$. The present work suggested that plants, which could biologically accumulate some chemical elements (such as alkaline or alkaline earth metals, as well as 
transition metals) acting as active Boudouard reaction catalysts, might provide fuels for DC-SOFCs in large quantity and good quality, with low cost and environmental friendliness.

\section{Acknowledgements}

This work was supported by the National Science Foundation of China (NSFC, No. 21276097), the Special Funds of Guangdong Province Public Research and Ability Construction (No. 2014A010106008), Guangdong Innovative and Entrepreneurial Research Team Program (No. 2014ZT05N200), and Program of Excellent Ph.D Thesis Authors of Guangdong Province. Sincere thanks to Lufeng Yang for experimental help.

\section{References}

[1] Guo M, Song W, Buhain J. Bioenergy and biofuels: History, status, and perspective. Renew Sust Energ Rev 2015; 42: 712-25.

[2] Steele BC, Heinzel A. Materials for fuel-cell technologies. Nature 2001; 414: 345-52.

[3] Frusteri F, Freni S, Chiodo V, Donato S, Bonura G, Cavallaro S. Steam and auto-thermal reforming of bio-ethanol over $\mathrm{MgO}$ and $\mathrm{Ni}$ supported catalysts. Int $\mathrm{J}$ Hydrogen Energ 2006; 31: 2193-9.

[4] Steele BCH. Fuel-cell technology: Running on natural gas. Nature 1999; 400: 619-21.

[5] Atkinson A, Barnett S, Gorte RJ, Irvine JTS, McEvoy AJ, Mogensen M, et al. Advanced 
anodes for high-temperature fuel cells. Nature Mater 2004; 3: 17-27.

[6] Murray EP, Tsai T, Barnett SA. A direct-methane fuel cell with a ceria-based anode. Nature 1999; 400: 649-51.

[7] Park S, Vohs JM, Gorte RJ. Direct oxidation of hydrocarbons in a solid-oxide fuel cell. Nature 2000; 404: 265-7.

[8] Xiao J, Xie Y, Liu J, Liu M. Deactivation of nickel-based anode in solid oxide fuel cells operated on carbon-containing fuels. J Power Sources 2014; 268: 508-16.

[9] Dicks AL. The role of carbon in fuel cells. J Power Sources 2006; 156: 128-41.

[10] Cao D, Sun Y, Wang G. Direct carbon fuel cell: Fundamentals and recent developments. J Power Sources 2007; 167: 250-7.

[11] Carlson, E.J. Program on technology innovation: systems assessment of direct carbon fuel cells technology. EPRI report. Palo Alto: EPRI 2006. CA 1013362.

[12] Rady AC, Giddey S, Badwal SP, Ladewig BP, Bhattacharya S. Review of fuels for direct carbon fuel cells. Energ Fuel 2012; 26: 1471-88.

[13] Giddey S, Badwal S, Kulkarni A, Munnings C. A comprehensive review of direct carbon fuel cell technology. Prog Energ Combust 2012; 38: 360-99.

[14] Gür TM. Critical review of carbon conversion in "carbon fuel cells". Chem Rev 2013; 113: 6179-206.

[15] Kacprzak A, Kobylecki R, Bis Z. Influence of temperature and composition of $\mathrm{NaOH}-\mathrm{KOH}$ and $\mathrm{NaOH}-\mathrm{LiOH}$ electrolytes on the performance of a direct carbon fuel cell. J Power Sources 2013; 239: 409-14.

[16] Guo L, Calo JM, Kearney C, Grimshaw P. The anodic reaction zone and performance of different carbonaceous fuels in a batch molten hydroxide direct carbon fuel cell. Appl 
Energy 2014; 129: 32-8.

[17] Zecevic S, Patton EM, Parhami P. Carbon-air fuel cell without a reforming process. Carbon 2004; 42: 1983-93.

[18] Cooper JF, Selman R. Electrochemical Oxidation of Carbon for Electric Power Generation: A Review. ECS Transactions 2009; 19: 15-25.

[19] Nabae Y, Pointon KD, Irvine JTS. Electrochemical oxidation of solid carbon in hybrid DCFC with solid oxide and molten carbonate binary electrolyte. Energy Environ Sci 2008; 1: $148-55$.

[20] Jayakumar A, Küngas R, Roy S, Javadekar A, Buttrey DJ, Vohs JM, et al. A direct carbon fuel cell with a molten antimony anode. Energy Environ Sci 2011; 4: 4133-7.

[21] Xu X, Zhou W, Liang F, Zhu Z. A comparative study of different carbon fuels in an electrolyte-supported hybrid direct carbon fuel cell. Appl Energy 2013; 108: 402-9.

[22] Hao W, He X, Mi Y. Achieving high performance in intermediate temperature direct carbon fuel cells with renewable carbon as a fuel source. Appl Energy 2014; 135: 174-81.

[23] Elleuch A, Halouani K, Li Y. Investigation of chemical and electrochemical reactions mechanisms in a direct carbon fuel cell using olive wood charcoal as sustainable fuel. J Power Sources 2015; 281: 350-61.

[24] Yu J, Zhao Y, Li Y. Utilization of corn cob biochar in a direct carbon fuel cell. J Power Sources 2014; 270: 312-7.

[25] Jain SL, Barry Lakeman J, Pointon KD, Marshall R, Irvine JTS. Electrochemical performance of a hybrid direct carbon fuel cell powered by pyrolysed MDF. Energy Environ Sci 2009; 2: 687-93.

[26] Jiang C, Ma J, Bonaccorso AD, Irvine JTS. Demonstration of high power, direct conversion of waste-derived carbon in a hybrid direct carbon fuel cell. Energy Environ 
Sci 2012; 5: 6973-80.

[27] Ahn SY, Eom SY, Rhie YH, Sung YM, Moon CE, Choi GM, et al. Utilization of wood biomass char in a direct carbon fuel cell (DCFC) system. Appl Energy 2013; 105: 207-16.

[28] Nakagawa N, Ishida M. Performance of an internal direct-oxidation carbon fuel cell and its evaluation by graphic exergy analysis. Ind Eng Chem Res 1988; 27: 1181-5.

[29] Xie Y, Tang Y, Liu J. A verification of the reaction mechanism of direct carbon solid oxide fuel cells. J Solid State Electrochem 2013; 17: 121-7.

[30] Tang Y, Liu J, Sui J. A novel direct carbon solid oxide fuel cell. ECS Transactions 2009; 25: 1109-14.

[31] Tang Y, Liu J. Fueling solid oxide fuel cells with activated carbon. Acta Phys-Chim Sin 2010; 26: 1191-4.

[32] Tang Y, Liu J. Effect of anode and Boudouard reaction catalysts on the performance of direct carbon solid oxide fuel cells. Int J Hydrogen Energ 2010; 35: 11188-93.

[33] Bai Y, Liu Y, Tang Y, Xie Y, Liu J. Direct carbon solid oxide Fuel Cell—a potential high performance battery. Int J Hydrogen Energ 2011; 36: 9189-94.

[34] Rady AC, Giddey S, Kulkarni A, Badwal SPS, Bhattacharya S, Ladewig BP. Direct carbon fuel cell operation on brown coal. Appl Energy 2014; 120: 56-64.

[35] Jiao Y, Tian W, Chen H, Shi H, Yang B, Li C, et al. In situ catalyzed Boudouard reaction of coal char for solid oxide-based carbon fuel cells with improved performance. Appl Energy 2015; 141: 200-8

[36] Zhang L, Xiao J, Xie Y, Tang Y, Liu J, Liu M. Behavior of strontium- and magnesium-doped gallate electrolyte in direct carbon solid oxide fuel cells. J Alloy Compd 2014; 608: 272-7. 
[37] Xie Y, Cai W, Xiao J, Tang Y, Liu J, Liu M. Electrochemical gas-electricity cogeneration through direct carbon solid oxide fuel cells. J Power Sources 2015; 277: 1-8.

[38] Cai W, Zhou Q, Xie Y, Liu J. A facile method of preparing Fe-loaded activated carbon fuel for direct carbon solid oxide fuel cells. Fuel 2015; 159: 887-93.

[39] Feighery AJ, Irvine JTS. Effect of alumina additions upon electrical properties of 8 mol.\% yttria-stabilised zirconia. Solid State Ionics 1999; 121: 209-16.

[40] Lei L, Bai Y, Liu J. Ni-based anode-supported Al2O3-doped-Y2O3-stabilized ZrO2 thin electrolyte solid oxide fuel cells with Y2O3-stabilized $\mathrm{ZrO} 2$ buffer layer. J Power Sources 2014; 248: 1312-9.

[41] Risnes H, Fjellerup J, Henriksen U, Moilanen A, Norby P, Papadakis K, et al. Calcium addition in straw gasification. Fuel 2003; 82: 641-51.

[42] Quyn DM, Hayashi J-i, Li C-Z. Volatilisation of alkali and alkaline earth metallic species during the gasification of a Victorian brown coal in CO2. Fuel Process Technol 2005; 86: $1241-51$

[43] Hippo E, Walker PL. Reactivity of heat-treated coals in carbon dioxide at $900{ }^{\circ} \mathrm{C}$. Fuel 1975; 54: 245-8.

[44] Lang RJ, Neavel RC. Behaviour of calcium as a steam gasification catalyst. Fuel 1982; 61: 620-6.

[45] Lahijani P, Zainal ZA, Mohammadi M, Mohamed AR. Conversion of the greenhouse gas $\mathrm{CO} 2$ to the fuel gas $\mathrm{CO}$ via the Boudouard reaction: A review. Renew Sust Energ Rev 2015; 41: 615-32.

[46] Huang Y, Yin X, Wu C, Wang C, Xie J, Zhou Z, et al. Effects of metal catalysts on CO2 gasification reactivity of biomass char. Biotechnol Adv 2009; 27: 568-72.

[47] Rao YK, Adjorlolo A, Haberman JH. On the mechanism of catalysis of the Boudouard 
reaction by alkali-metal compounds. Carbon 1982; 20: 207-12.

[48] Zhang Y, Ashizawa M, Kajitani S. Calcium loading during the dewatering of wet biomass in kerosene and catalytic activity for subsequent char gasification. Fuel 2008; 87: 3024-30. 
Figure captions:

Fig. 1. Schematic illustration of the reaction mechanism of a DC-SOFC.

Fig. 2. Morphology change of the leaf biochar during the pre-treatment process.

Fig. 3. SEM pictures of cross section (a) and anode (b) of an as- prepared SOFC.

Fig. 4. Cell performance plot with error bars (a) and impedance spectra (b) of the as-prepared SOFC powered by hydrogen at $850^{\circ} \mathrm{C}$.

Fig. 5. Electrochemical characteristics of DC-SOFCs fuelled by leaf char, Fe-loaded activated carbon, pure activated carbon, and simulated leaf char, respectively, at $850{ }^{\circ} \mathrm{C}$. (a) Output performances (with representative error bars); (b) AC impedance spectra.

Fig. 6. The discharging curves, with error bars, of DC-SOFCs respectively with $0.5 \mathrm{~g}$ leaf char, Fe-loaded activated carbon and simulated leaf char as fuel, operated at constant current of $0.2 \mathrm{~A}\left(0.22 \mathrm{~A} \mathrm{~cm}^{-2}\right)$, at $850^{\circ} \mathrm{C}$.

Fig. 7. SEM micrographs showing the porous structure of leaf char (a) and activated carbon (b).

Fig. 8. The Raman spectra of leaf char and activated carbon.

Fig. 9. X-ray diffraction spectra for leaf char.

Fig. 10. Element distribution diagram for leaf char. 
Fig. 11. Thermogravimetric and differential thermal curves of the leaf char.

Fig. 12. Schematic illustration of catalyst distribution in leaf-char (a) and artificial catalyst-loaded carbon (b), respectively. (Black colour represents carbon, white represents natural $\mathrm{Ca}$, and red represents artificial catalyst.)

Fig. 13. EDX surface scanning element distribution mapping pictures of the leaf char.

Table caption:

Table 1 The components of leaf char after discharging test. 
Supplementary Interactive Plot Data (CSV)
Click here to download Supplementary Inte

Click here to download Supplementary Interactive Plot Data (CSV): Supplementary Information-V.docx 


\section{Figure captions:}

Fig. 1. Schematic illustration of the reaction mechanism of a DC-SOFC.

Fig. 2. Morphology change of the leaf biochar during the pre-treatment process.

Fig. 3. SEM pictures of cross section (a) and anode (b) of an as- prepared SOFC.

Fig. 4. Cell performance plot with error bars (a) and impedance spectra (b) of the as-prepared SOFC powered by hydrogen at $850^{\circ} \mathrm{C}$.

Fig. 5. Electrochemical characteristics of DC-SOFCs fuelled by leaf char, Fe-loaded activated carbon, pure activated carbon, and simulated leaf char, respectively, at $850{ }^{\circ} \mathrm{C}$. (a) Output performances (with representative error bars); (b) AC impedance spectra.

Fig. 6. The discharging curves, with error bars, of DC-SOFCs respectively with $0.5 \mathrm{~g}$ leaf char, Fe-loaded activated carbon and simulated leaf char as fuel, operated at constant current of $0.2 \mathrm{~A}\left(0.22 \mathrm{~A} \mathrm{~cm}^{-2}\right)$, at $850^{\circ} \mathrm{C}$.

Fig. 7. SEM micrographs showing the porous structure of leaf char (a) and activated carbon (b).

Fig. 8. The Raman spectra of leaf char and activated carbon.

Fig. 9. X-ray diffraction spectra for leaf char.

Fig. 10. Element distribution diagram for leaf char.

Fig. 11. Thermogravimetric and differential thermal curves of the leaf char.

Fig. 12. Schematic illustration of catalyst distribution in leaf-char (a) and artificial catalyst-loaded carbon (b), respectively. (Black colour represents carbon, white 
represents natural $\mathrm{Ca}$, and red represents artificial catalyst.)

Fig. 13. EDX surface scanning element distribution mapping pictures of the leaf char. 
Fig. 1
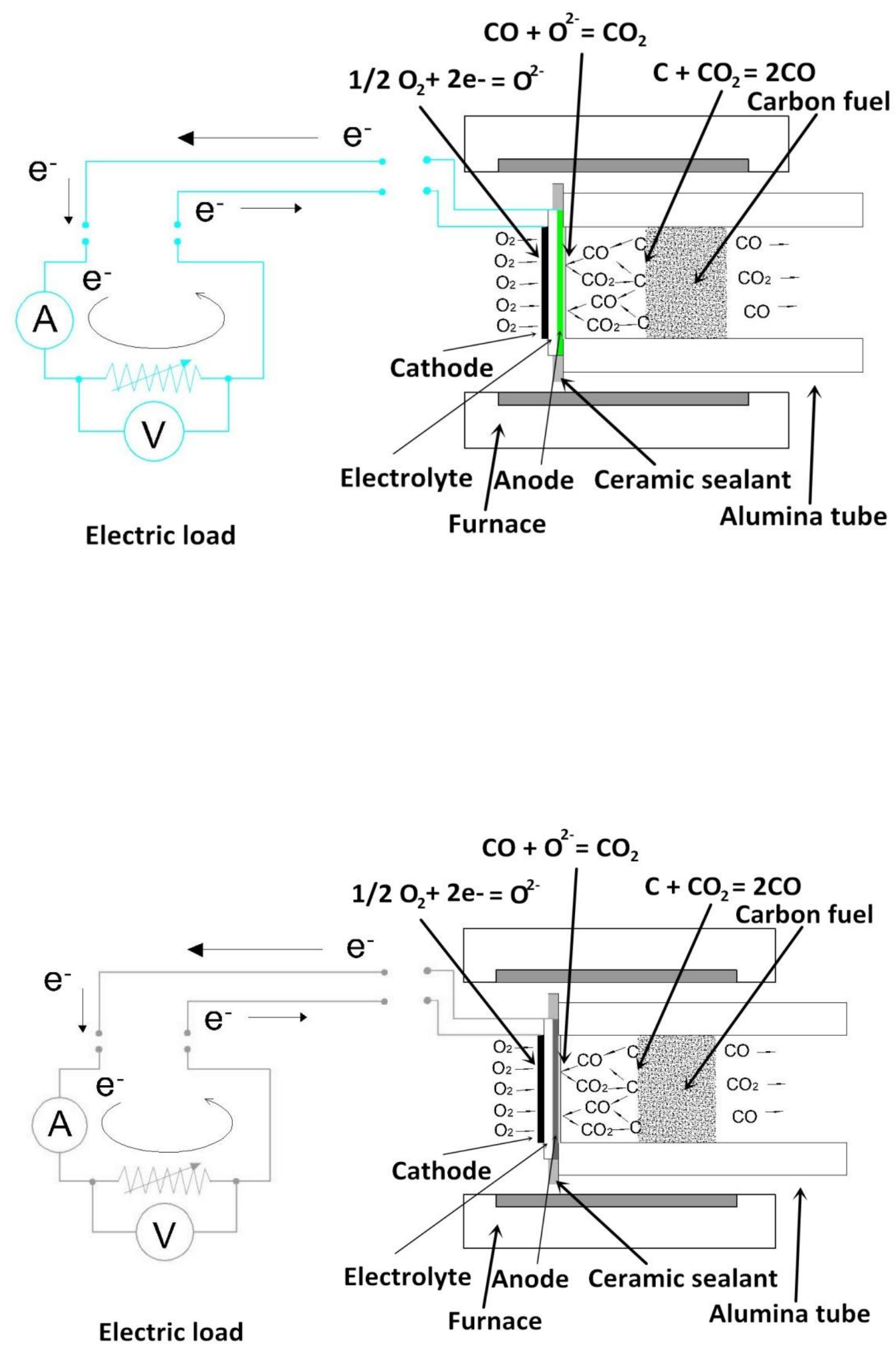
Fig. 2
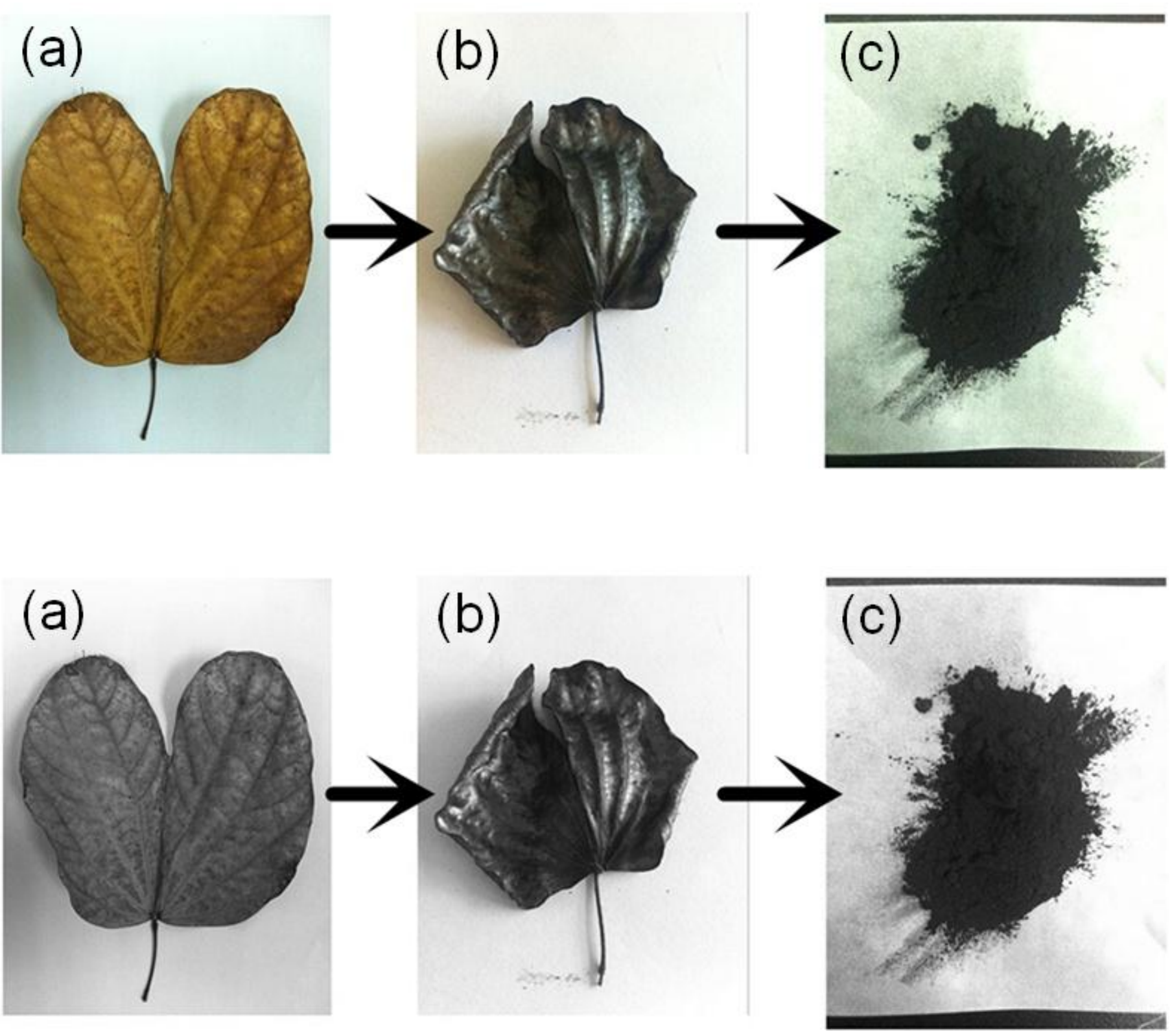
Fig. 3
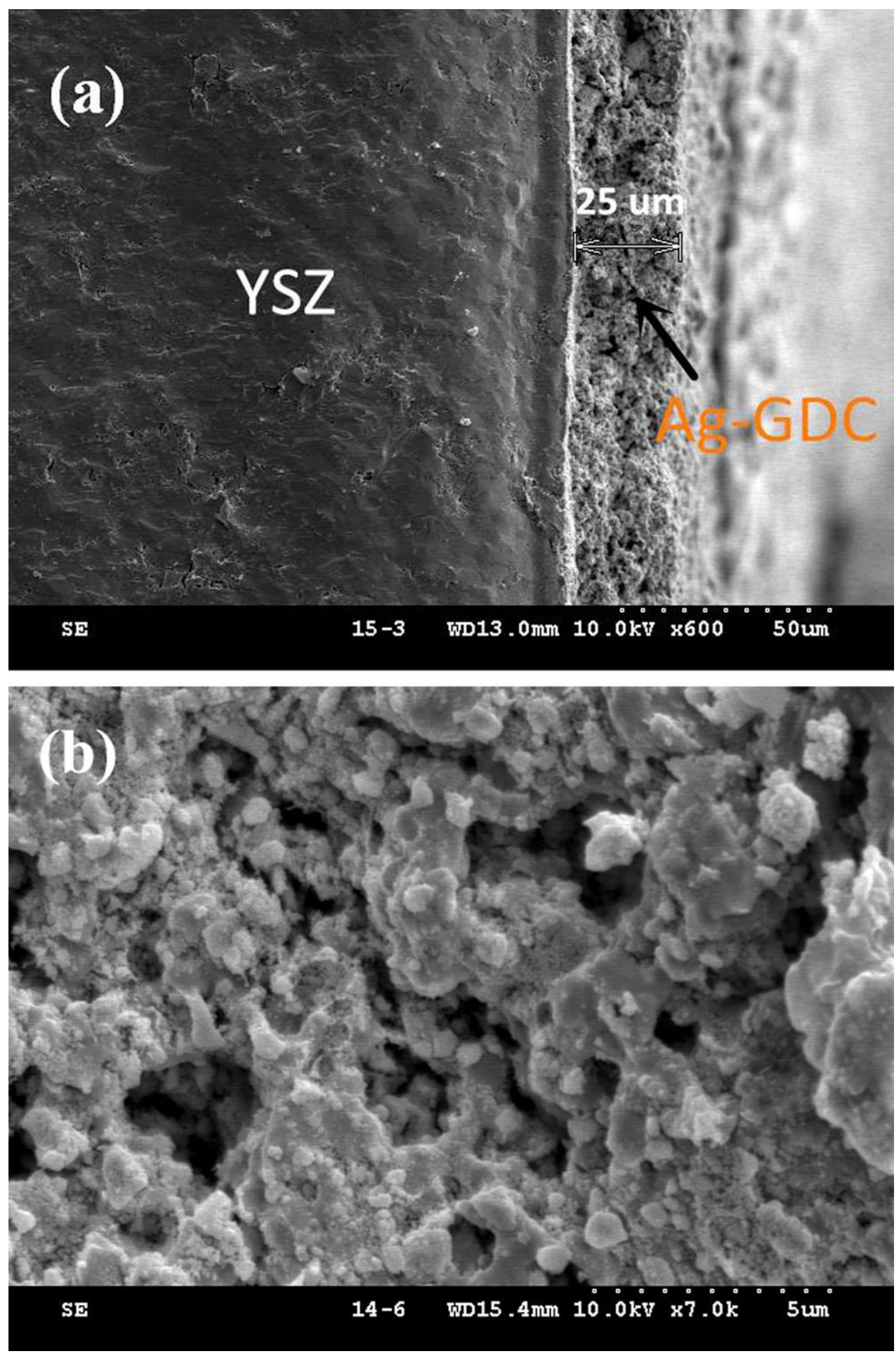

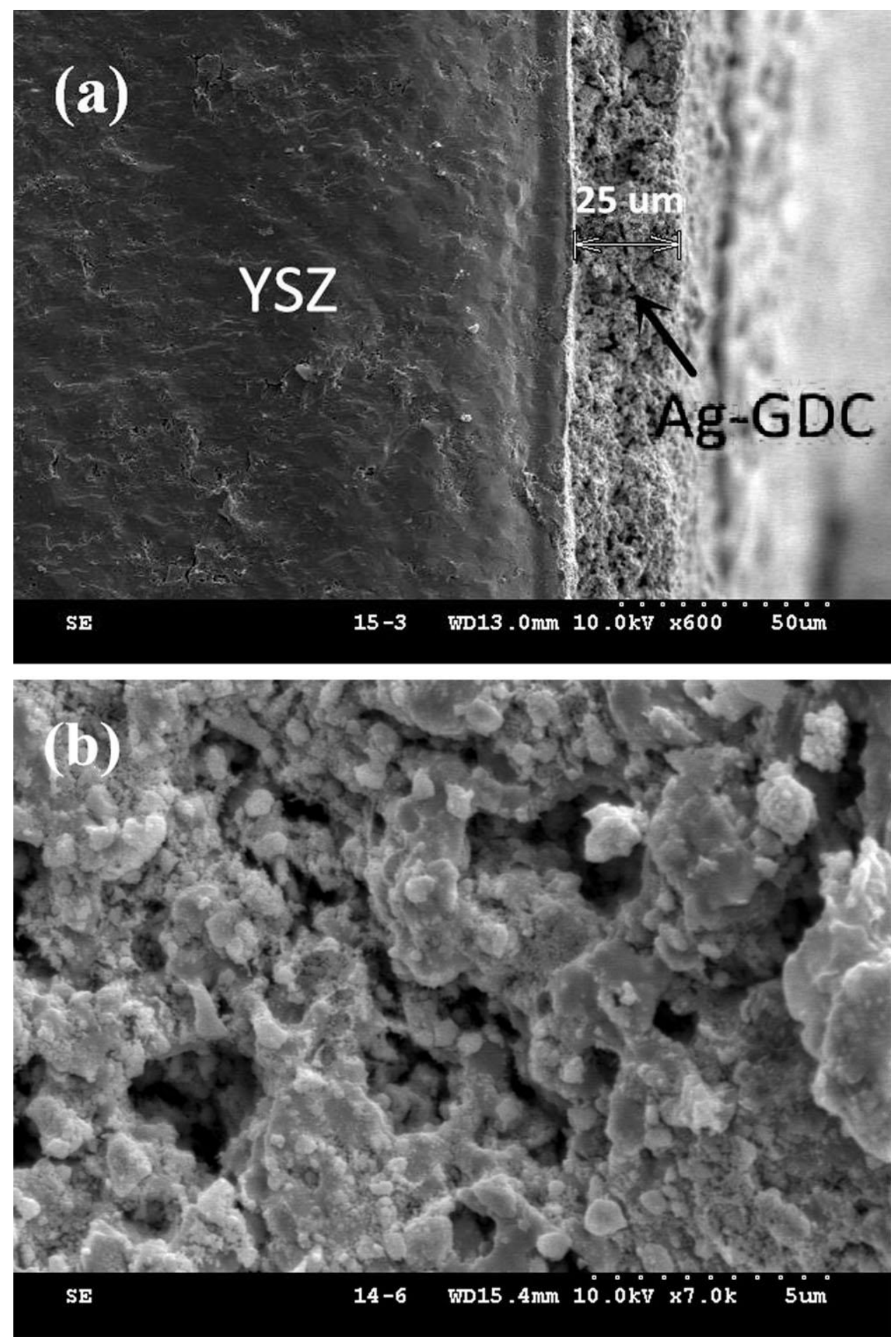

Fig. 4 
(a)
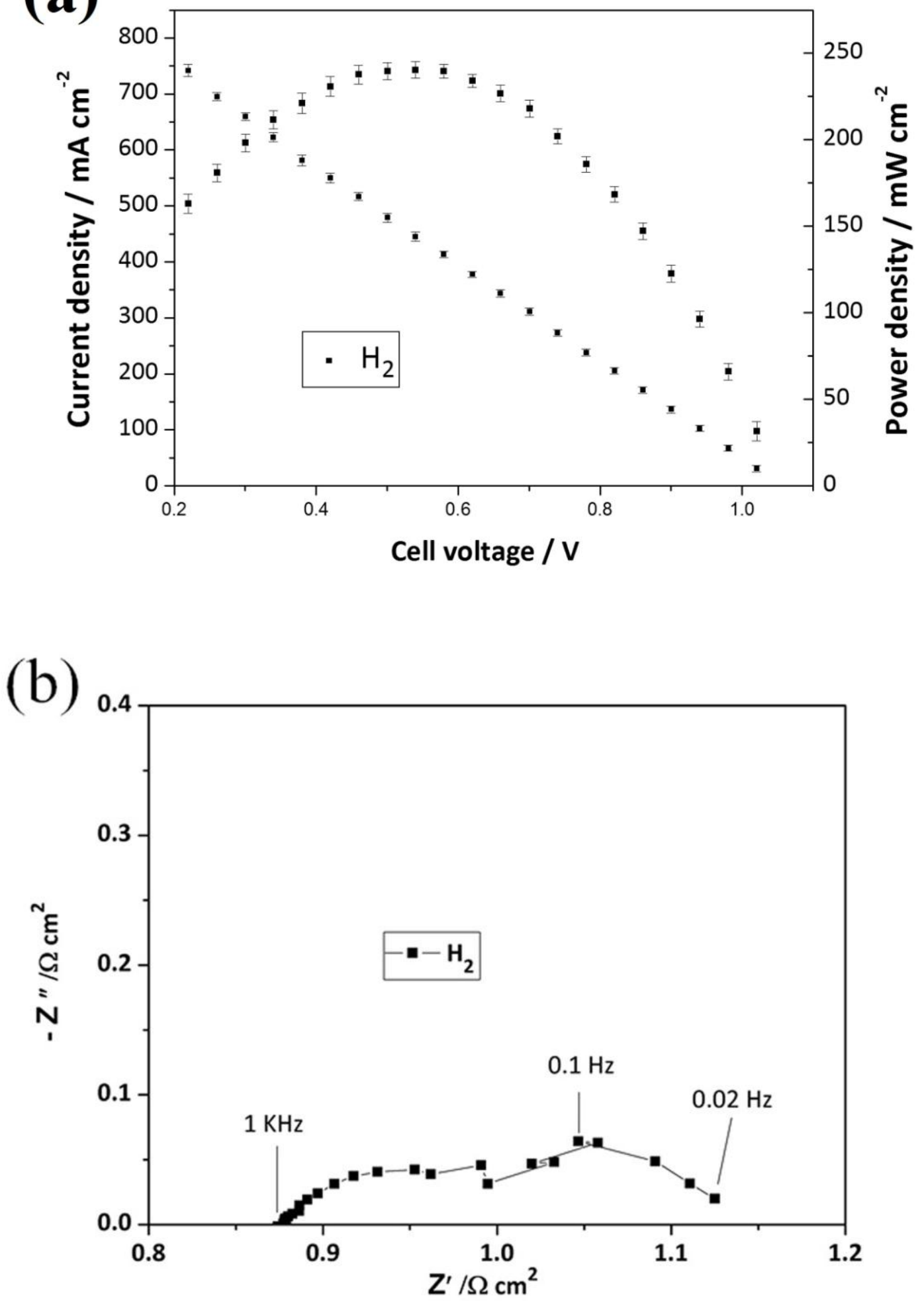

Fig. 5 


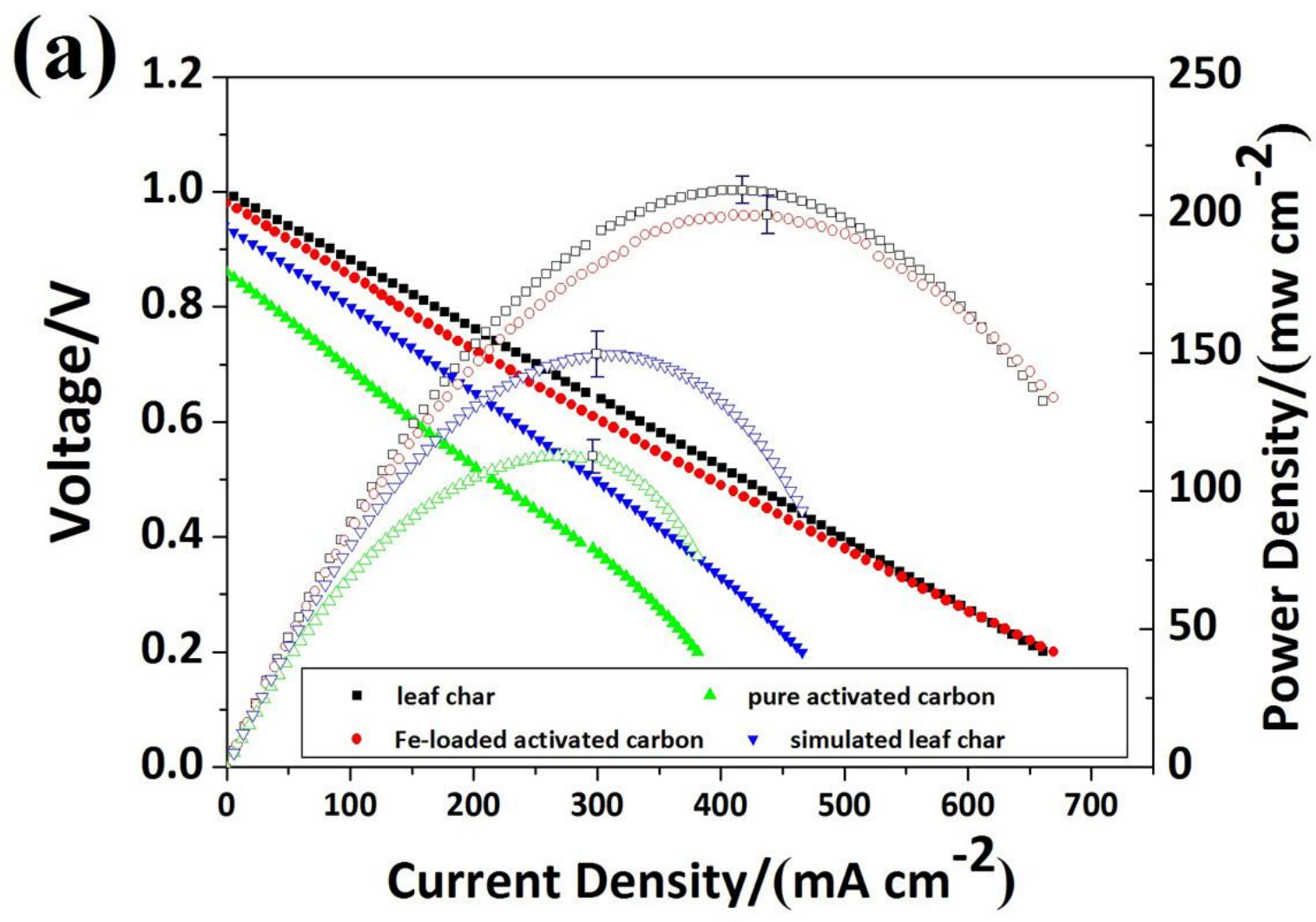

(b)

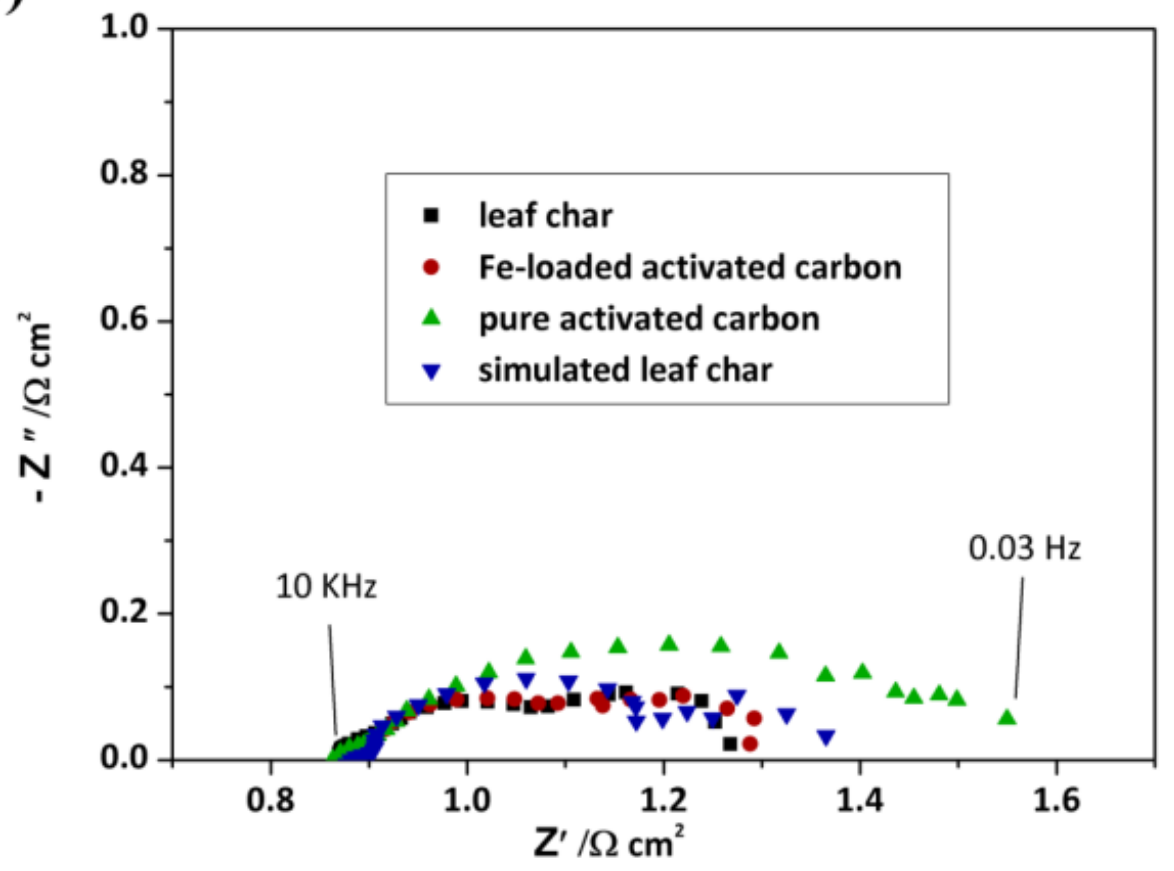




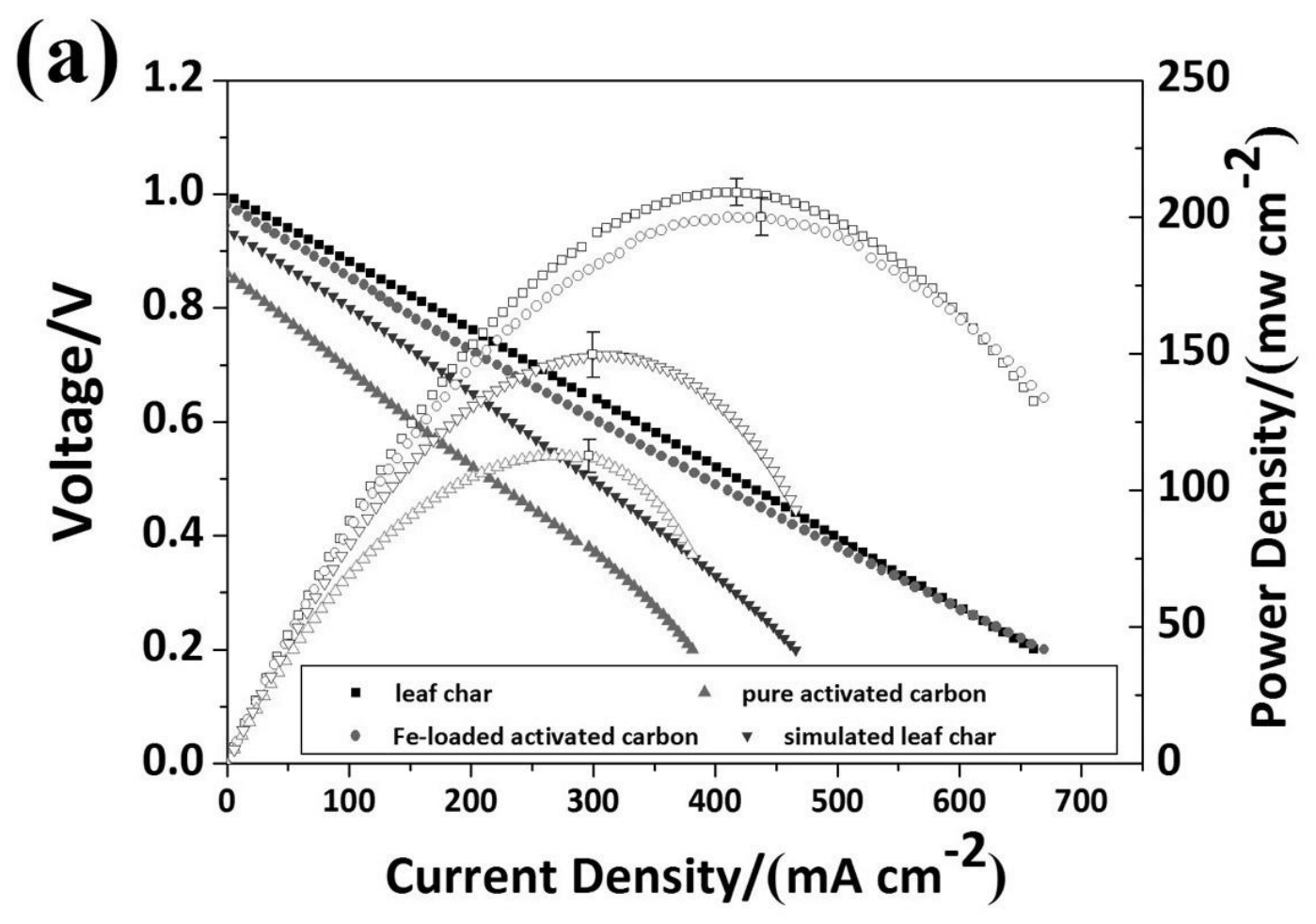

(b)

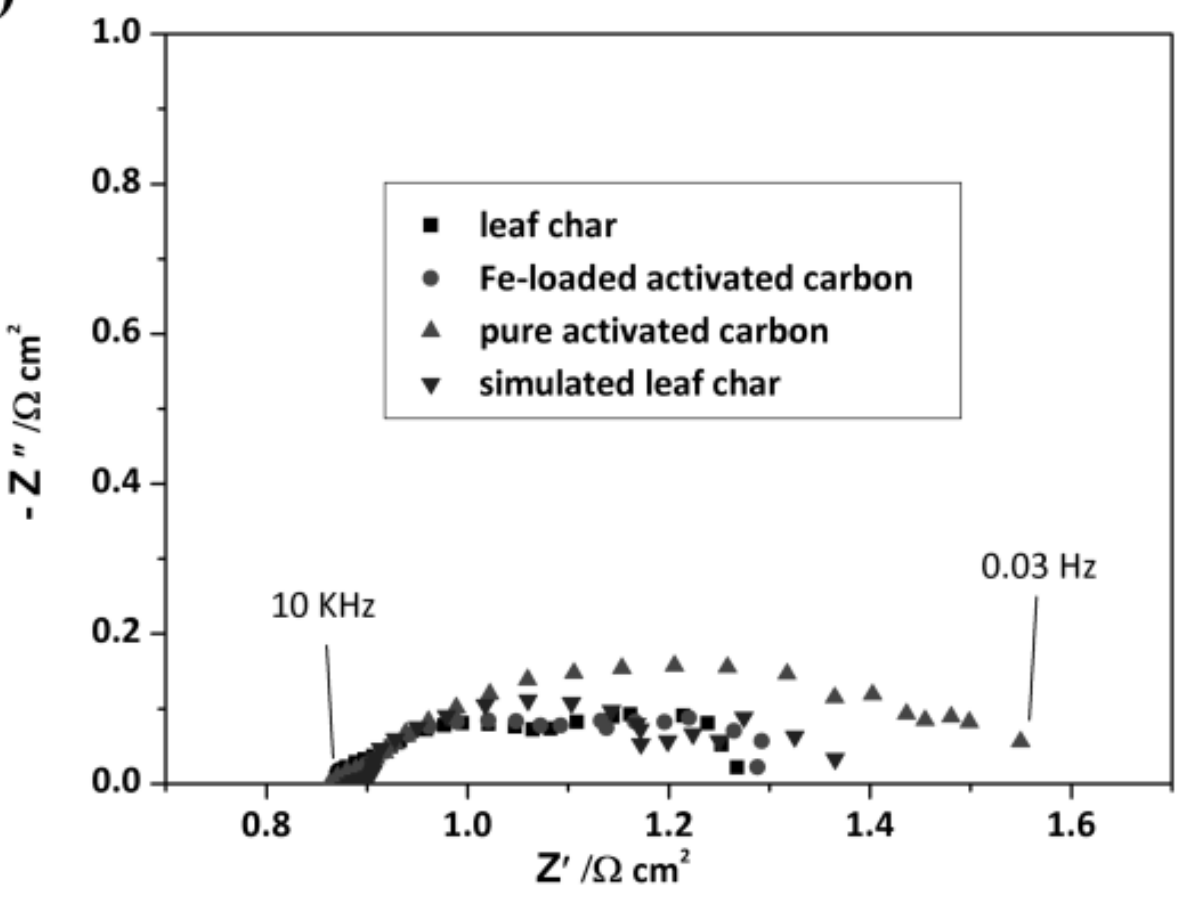


Fig. 6
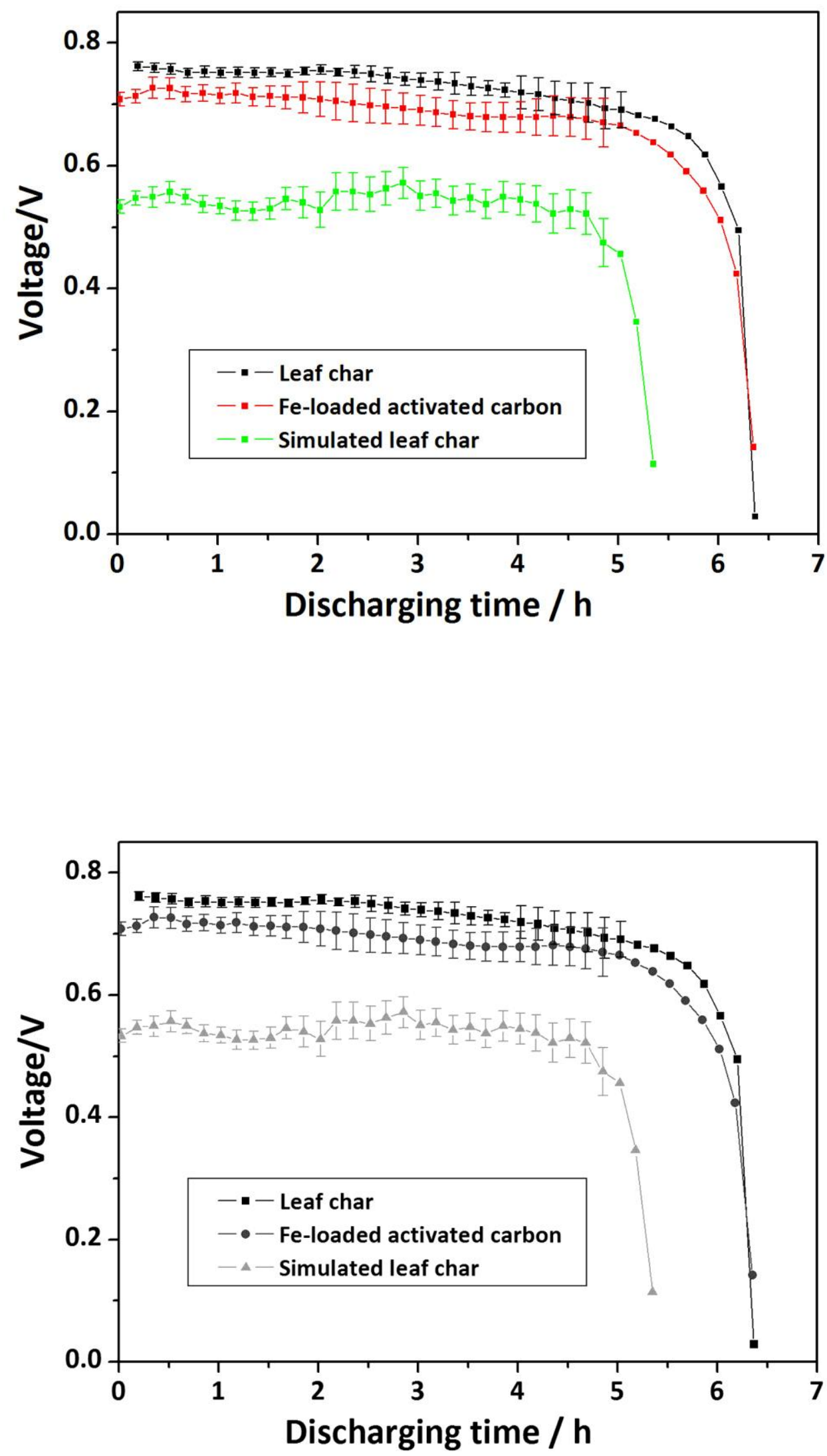
Fig. 7
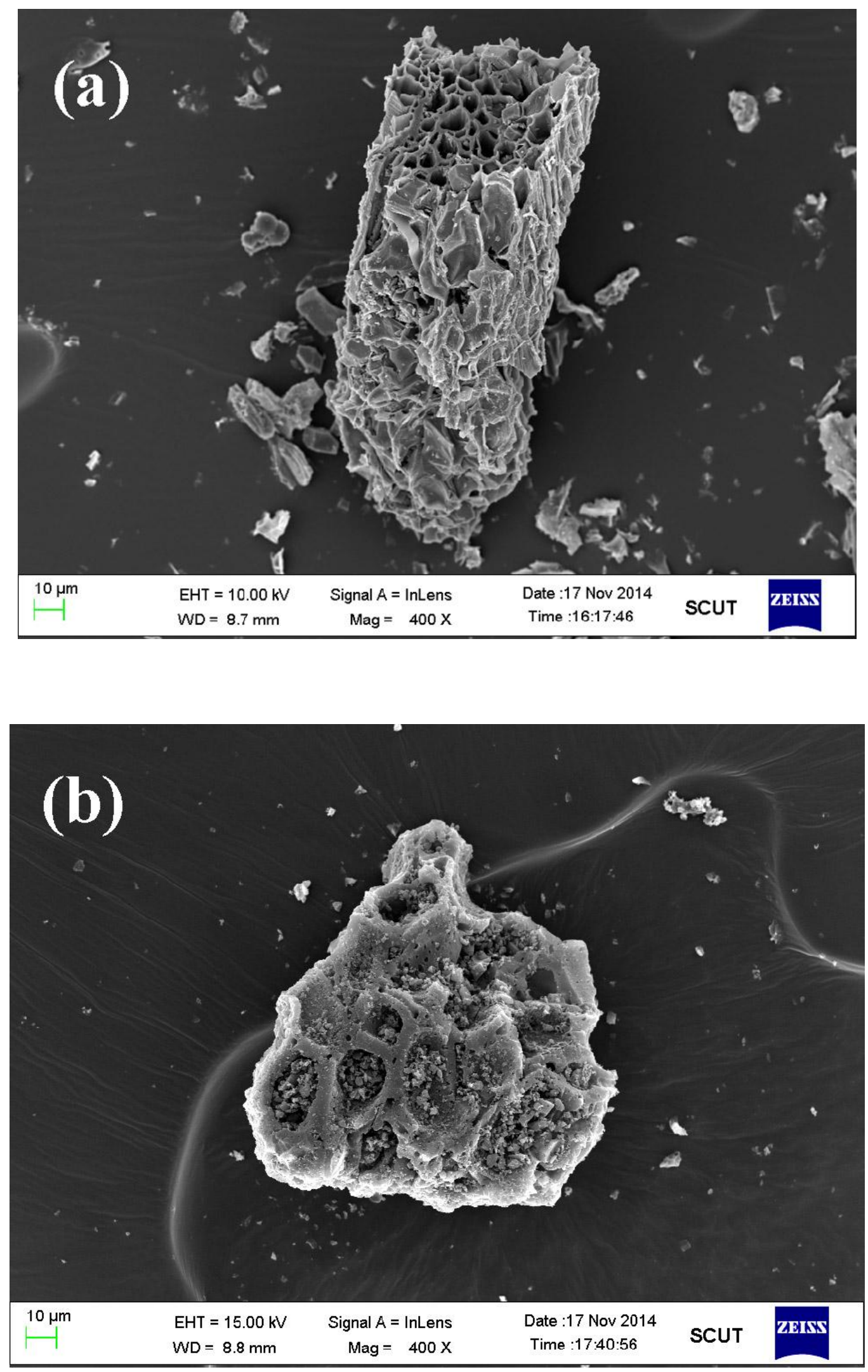

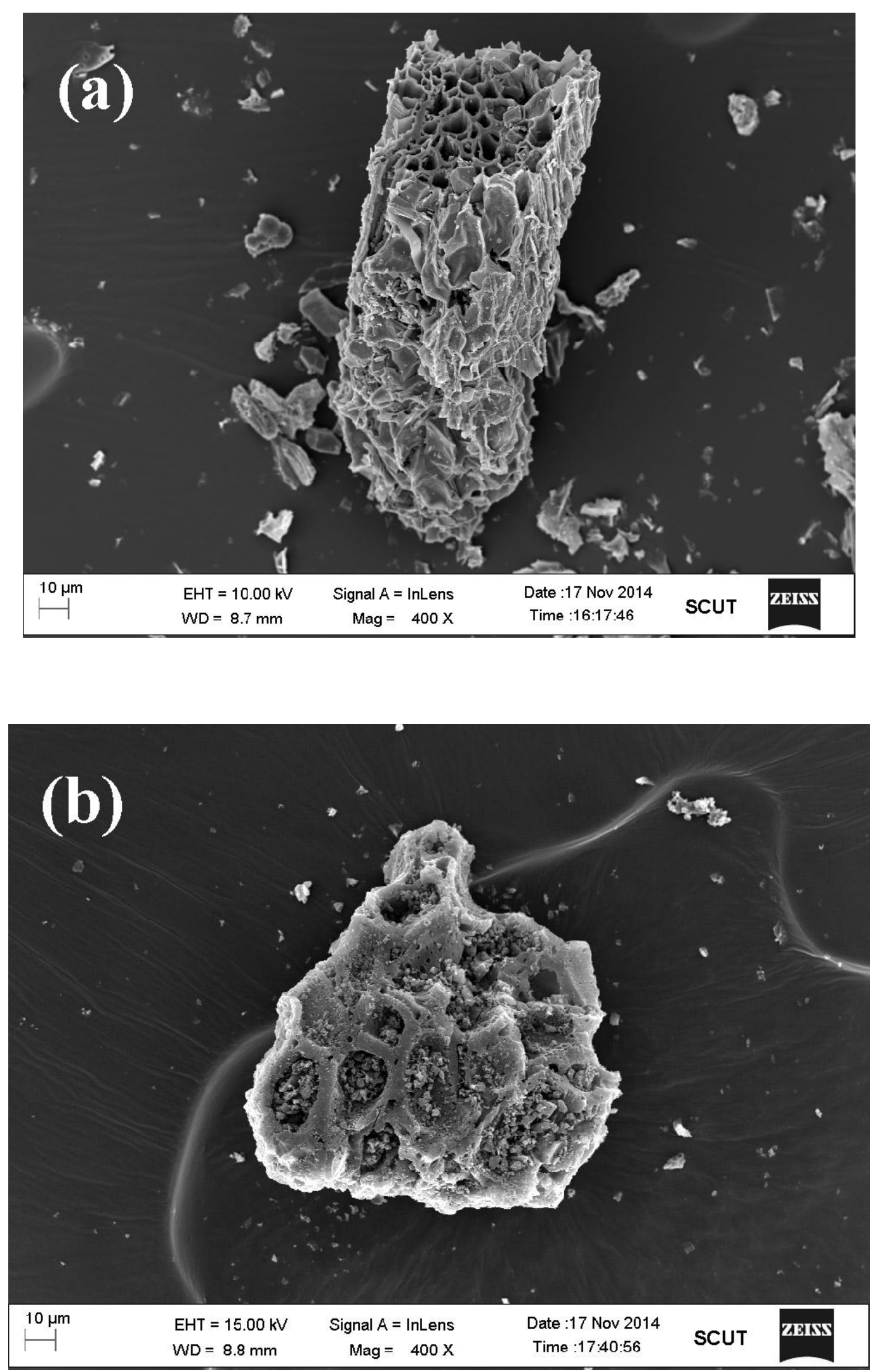
Fig. 8
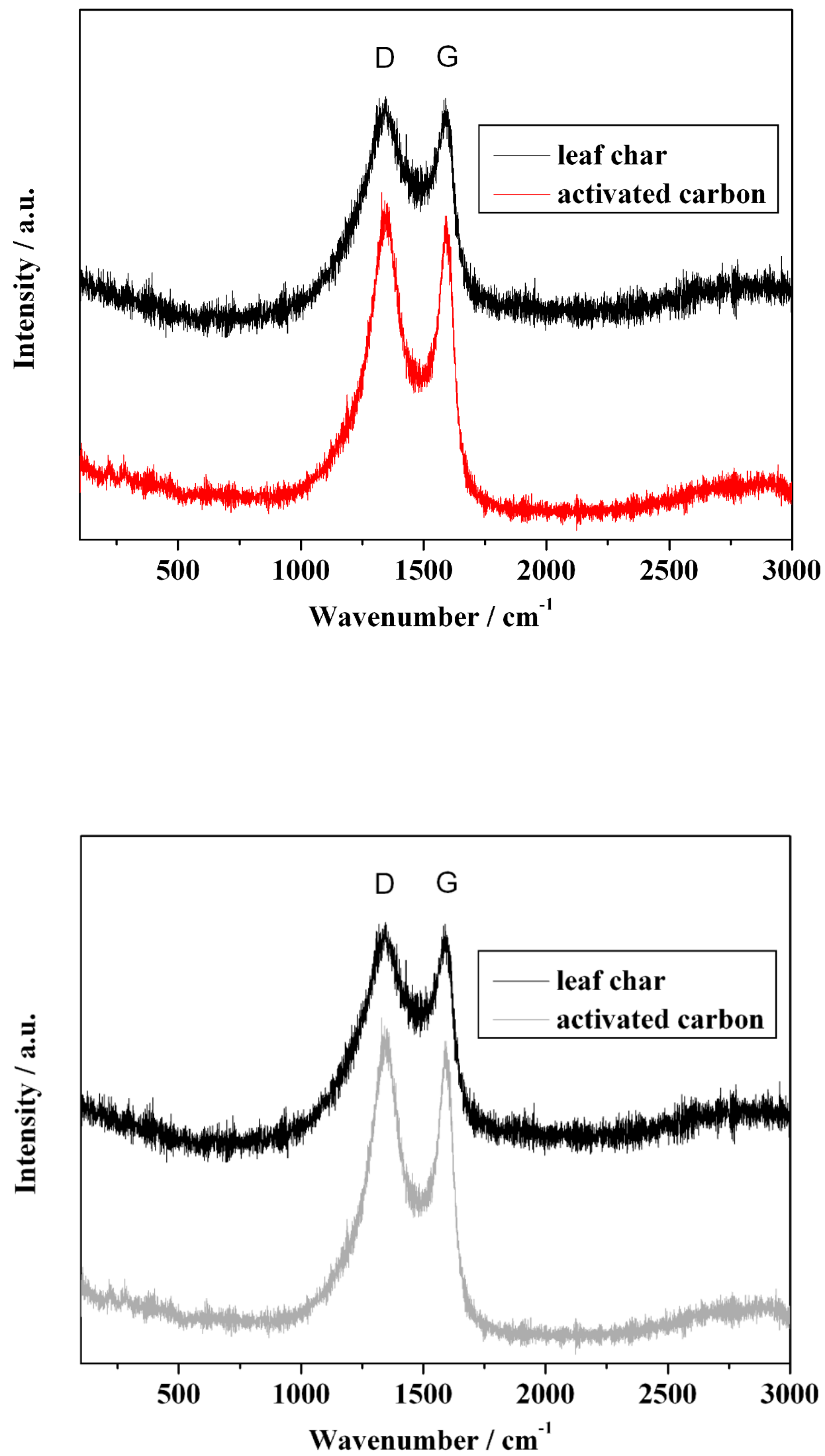
Fig. 9

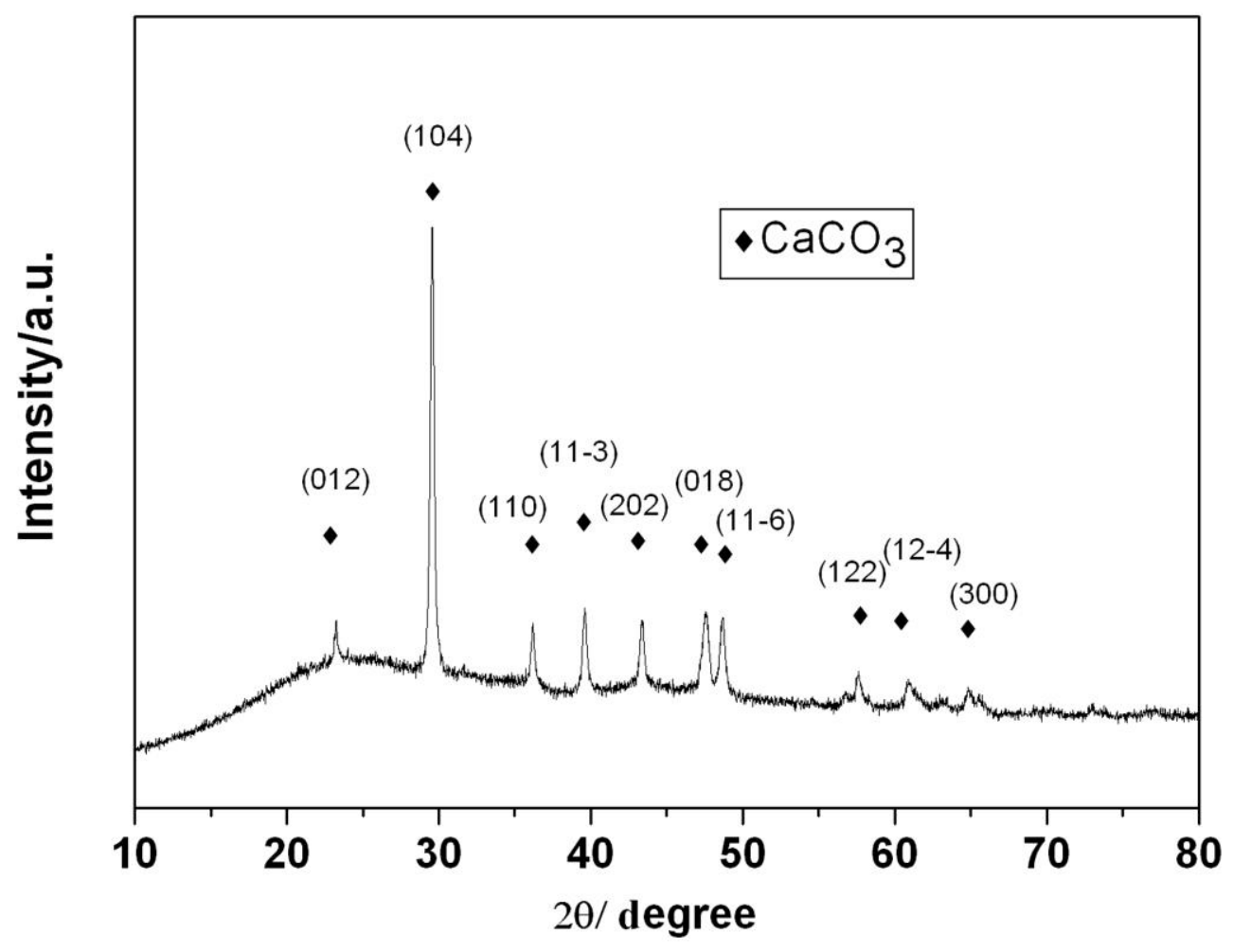


Fig. 10
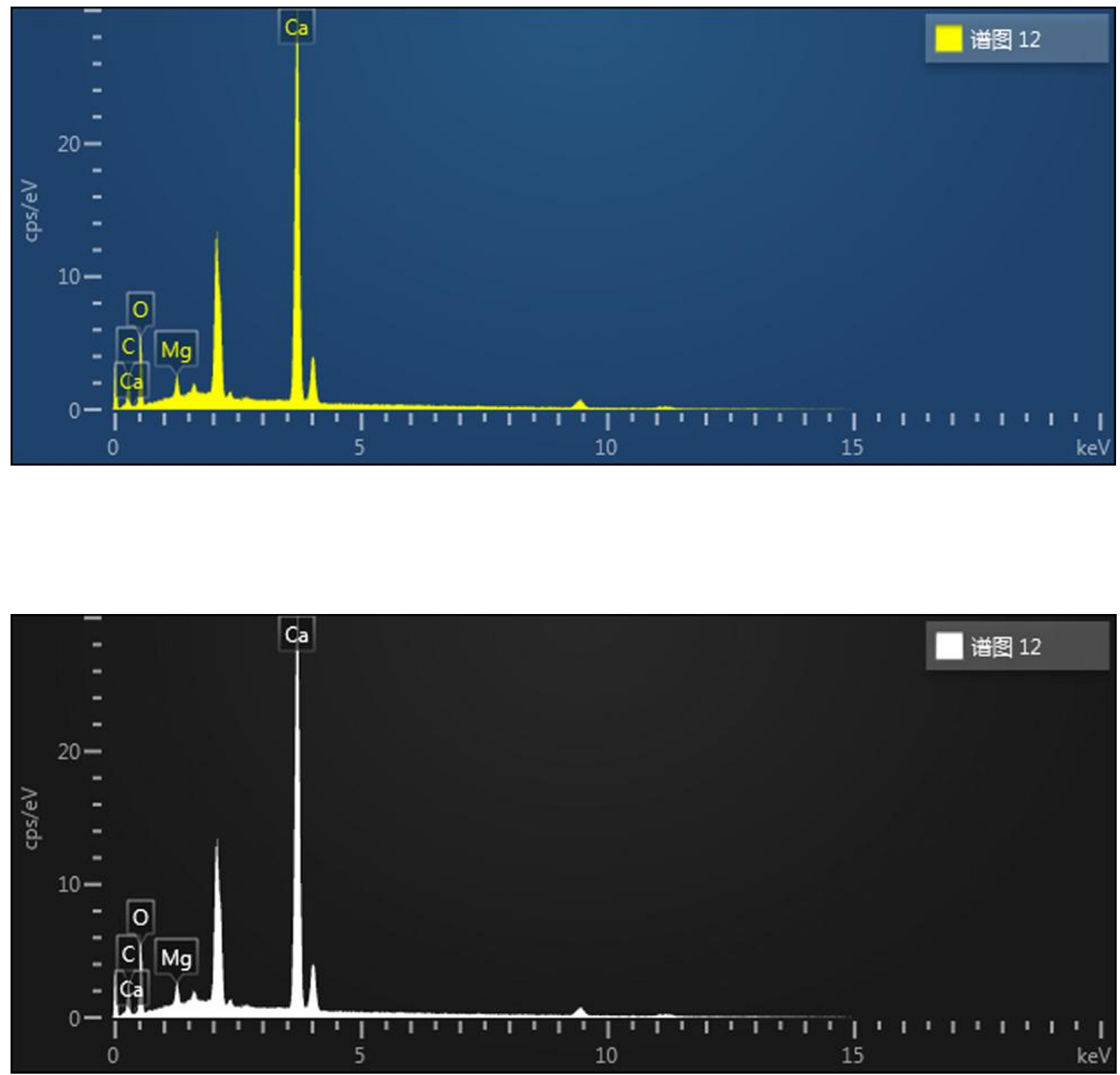
Fig. 11
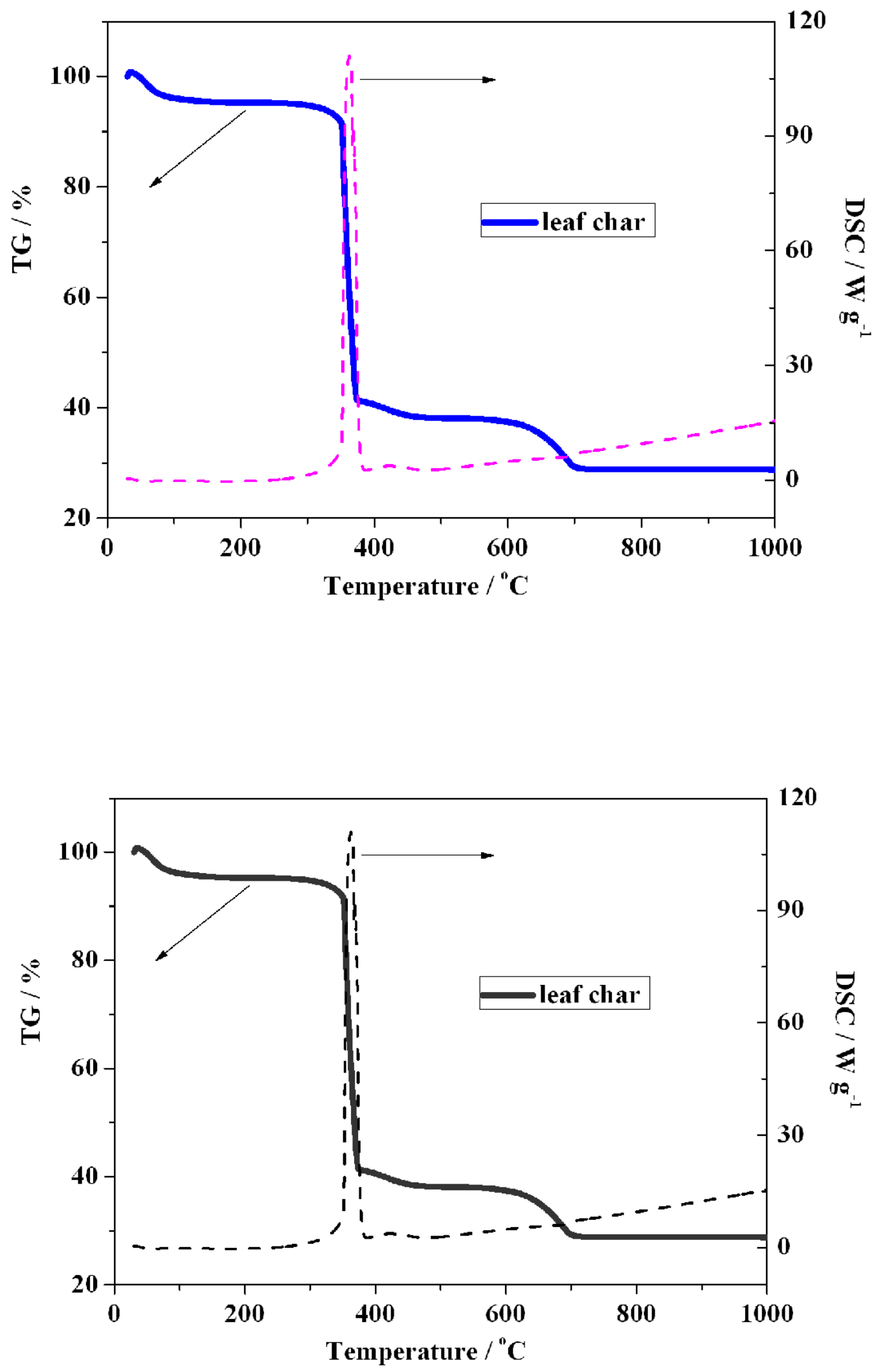
Fig. 12
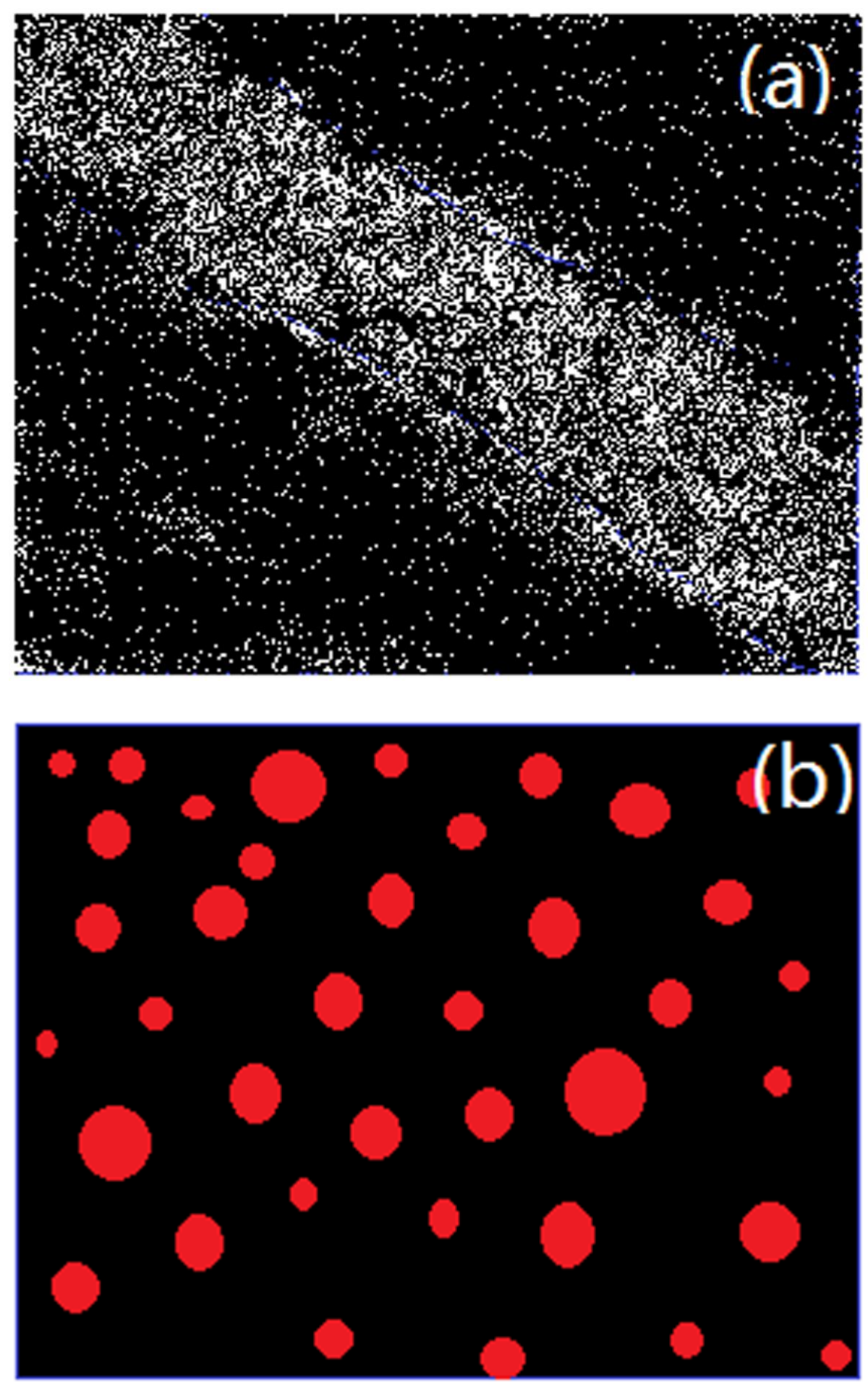


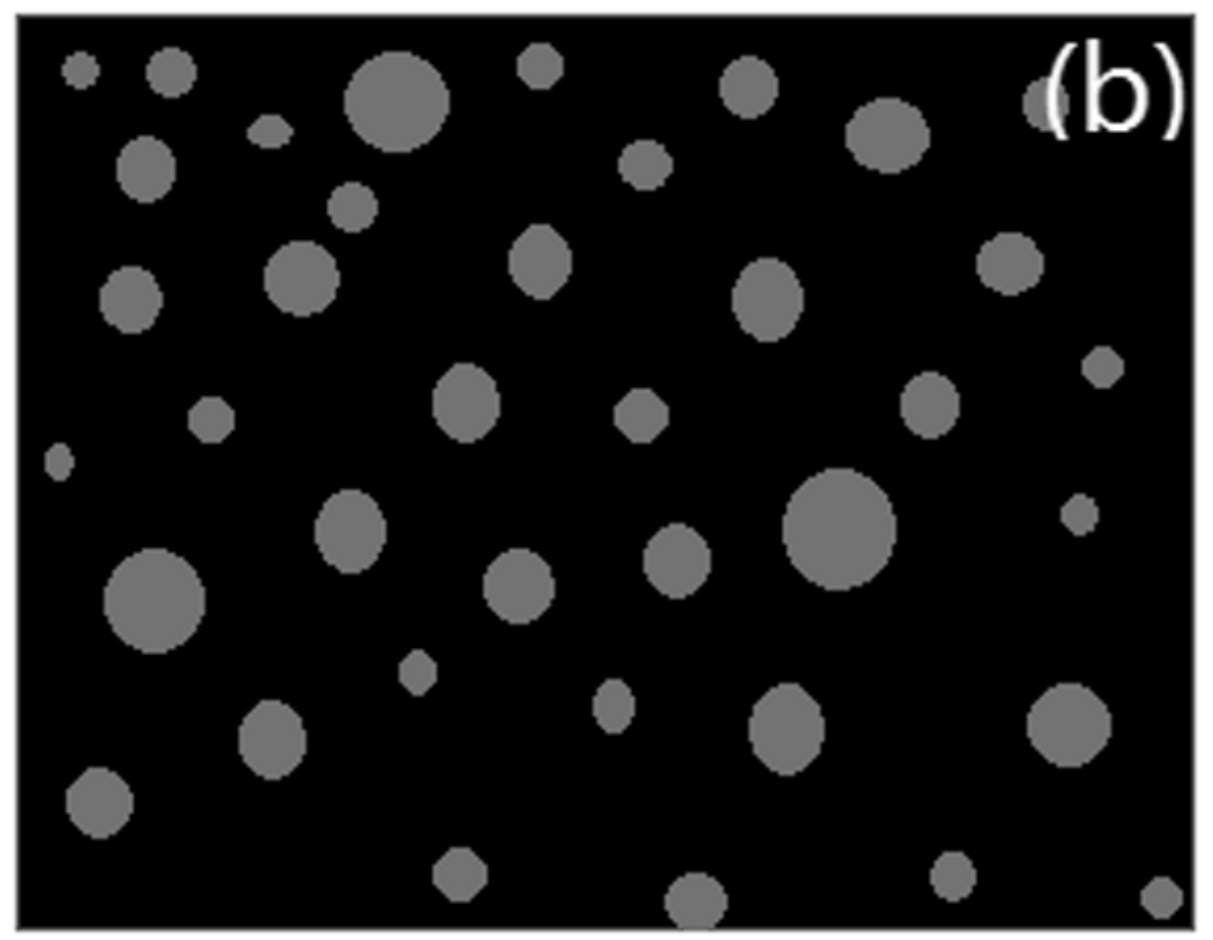


Fig. 13

电子图像 1
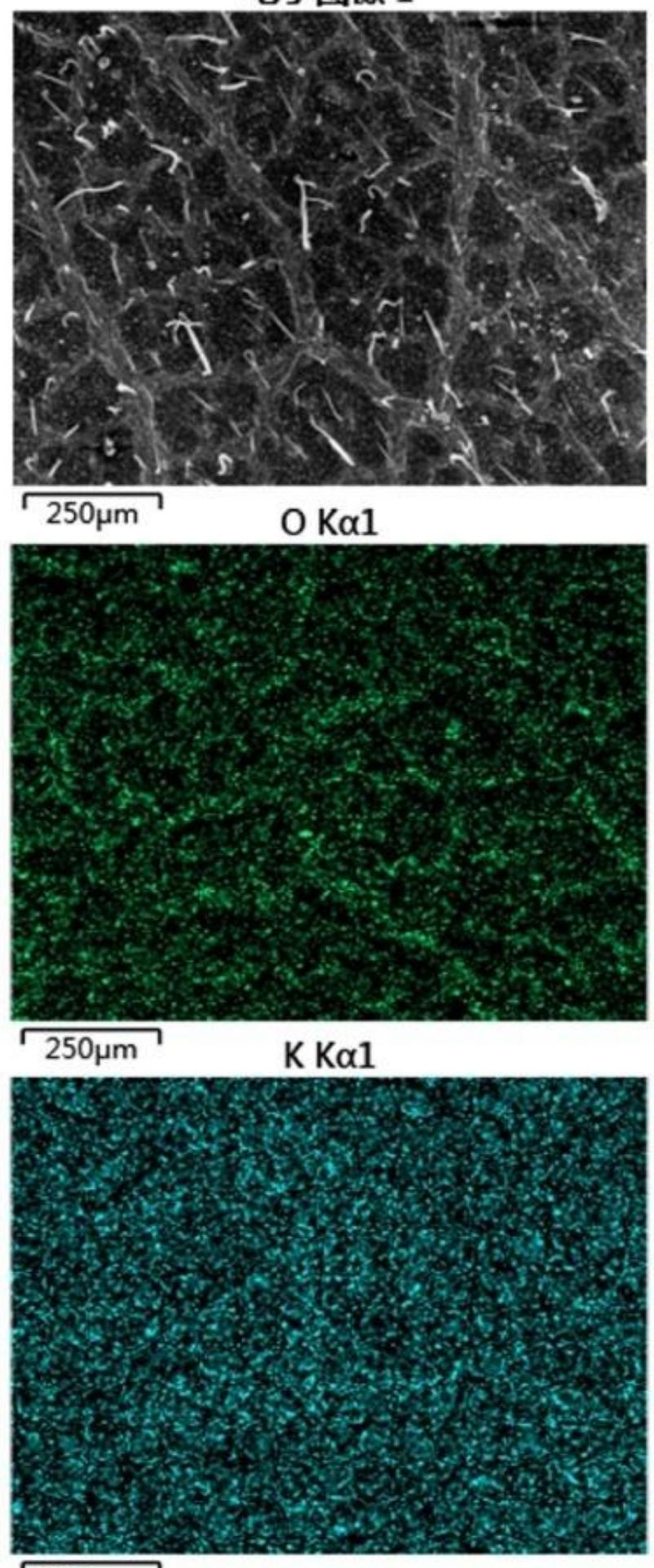

$\longdiv { 2 5 0 \mu \mathrm { m } }$
C Ka1 2

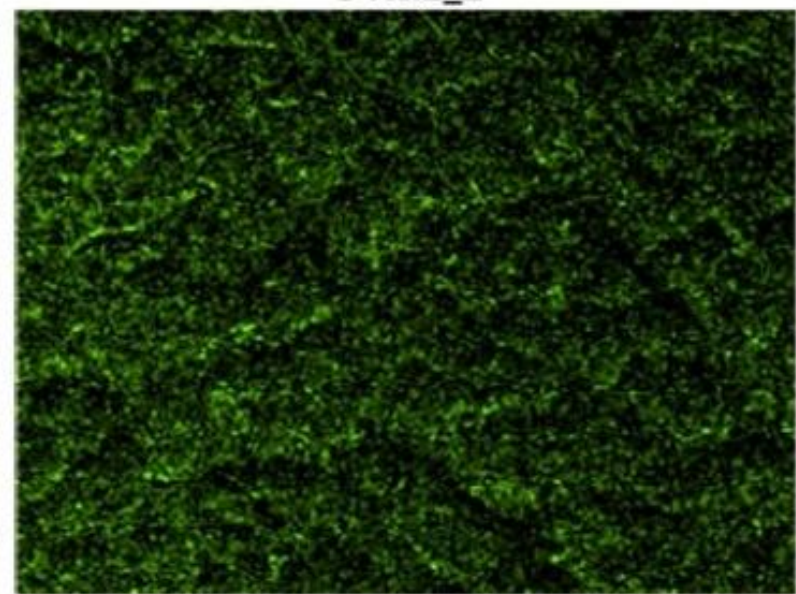

$\mathrm{Ca} K \alpha 1$

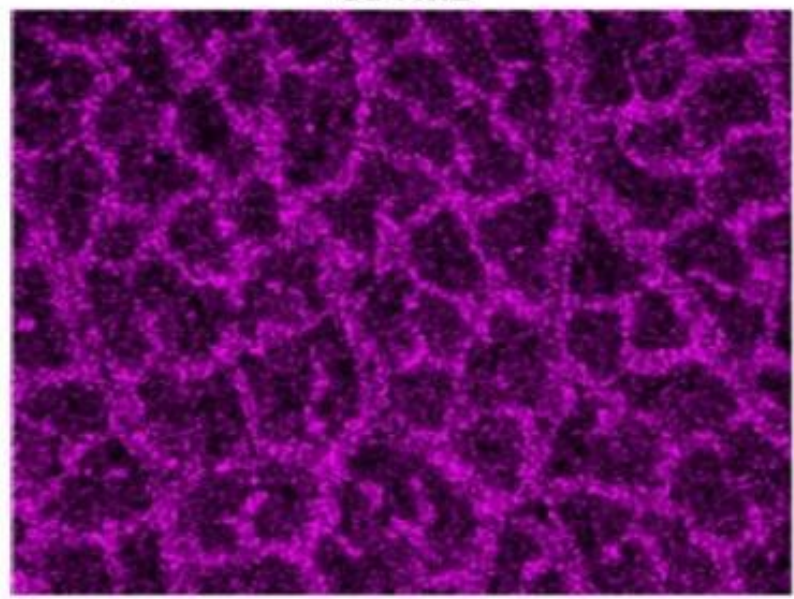

$\sqrt{250 \mu \mathrm{m}} \quad \mathrm{Mg} \mathrm{K \alpha} 1 \_2$

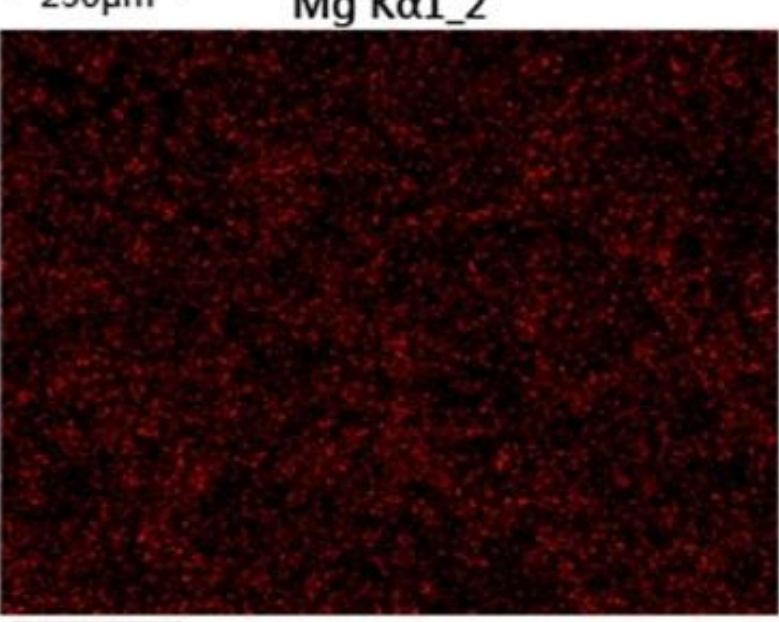

$\longdiv { 2 5 0 \mu \mathrm { m } }$ 
电子图像 1
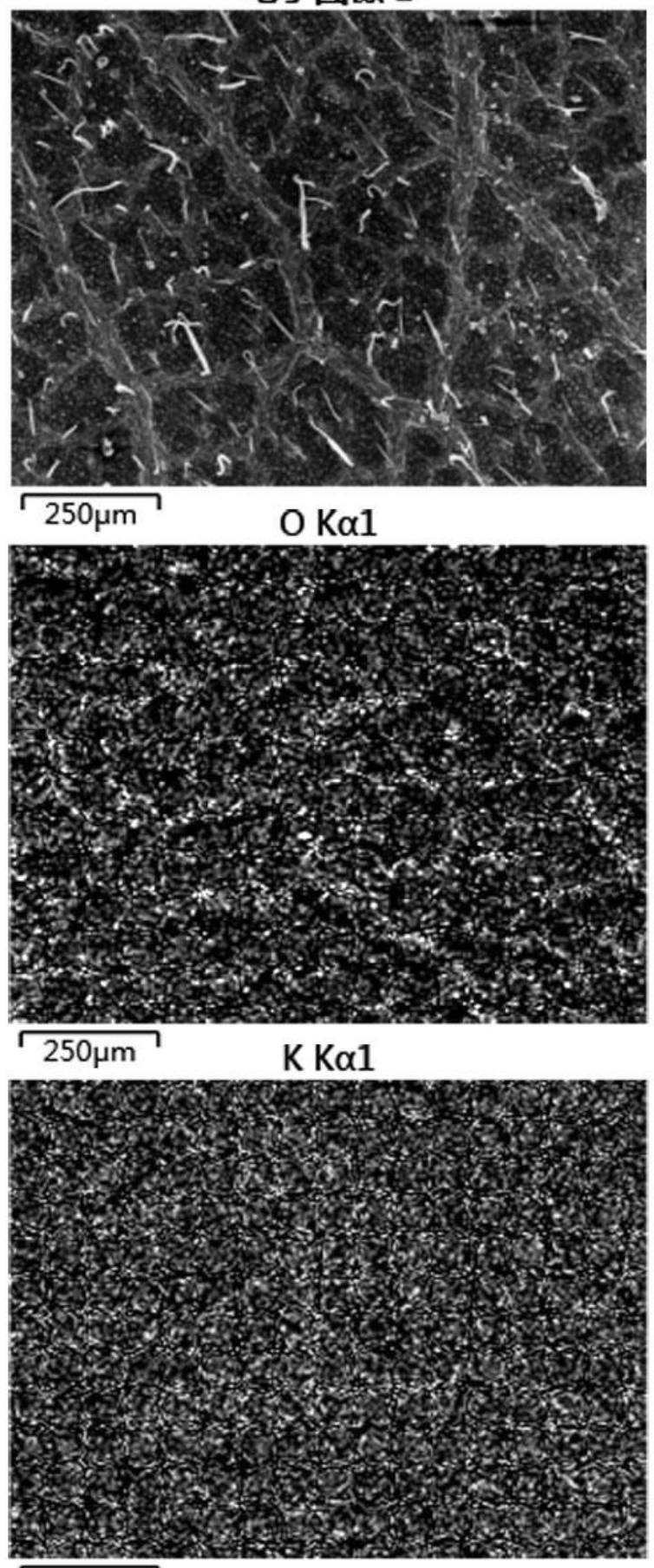

$250 \mu \mathrm{m}$
C K $\alpha 12$

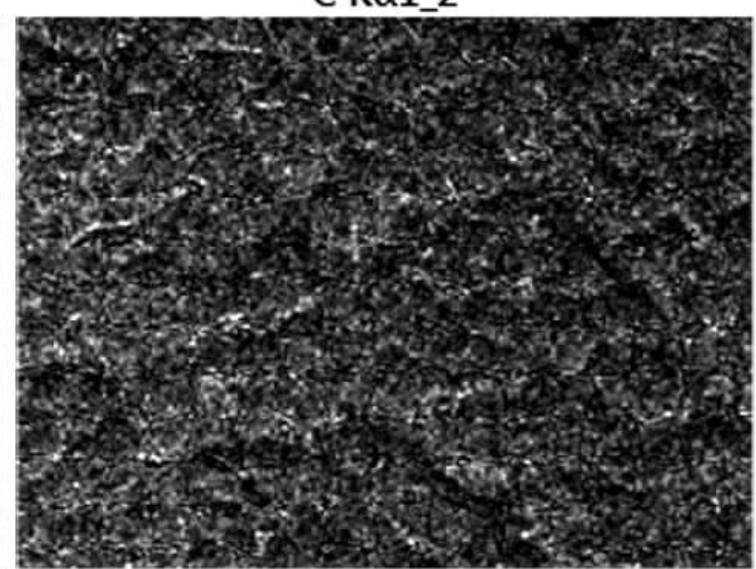

\section{$\sqrt{250 \mu \mathrm{m}} \quad \mathrm{Ca} \mathrm{K} \alpha 1$}

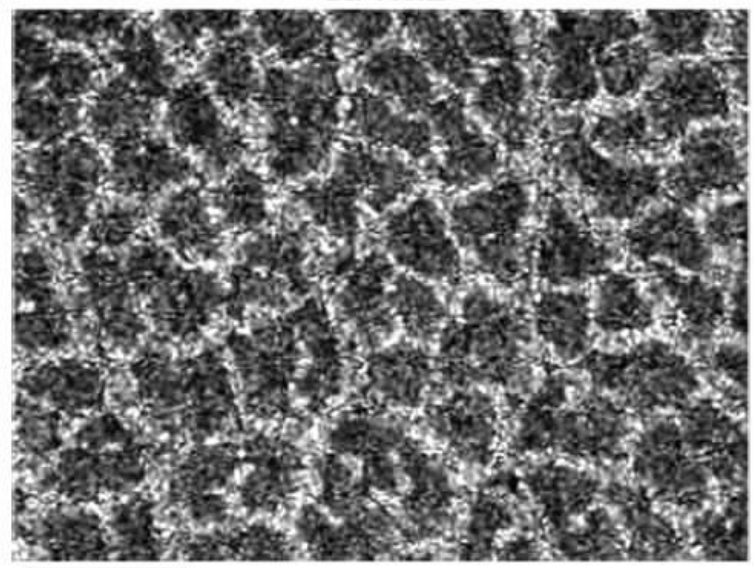

$\sqrt{250 \mu \mathrm{m}} \quad \mathrm{Mg} \mathrm{K \alpha 1} 2$

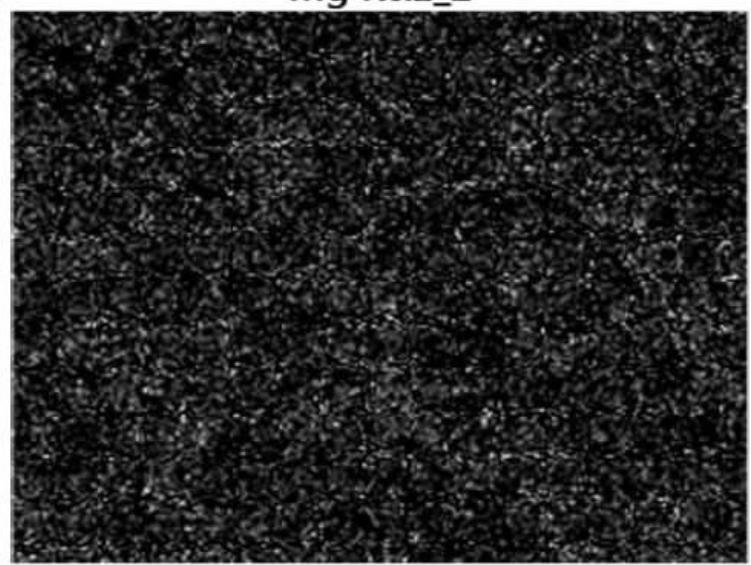

$\longdiv { 2 5 0 \mu \mathrm { m } }$ 
Table 1

The components of leaf char after discharging test.

\begin{tabular}{llllll}
\hline Element & $\mathrm{C}$ & $\mathrm{O}$ & $\mathrm{Mg}$ & $\mathrm{K}$ & $\mathrm{Ca}$ \\
\hline $\mathrm{Wt} \%$ & 12.99 & 47.4 & 1.07 & 2.22 & 36.32 \\
$\mathrm{At} \%$ & 21.4 & 58.6 & 0.9 & 1.1 & 18 \\
\hline
\end{tabular}


Graphical Abstract (for review)

Graphical abstract

A plant-derived biochar, with biologically accumulated chemical elements as catalyst for the Boudouard reaction, is a superior fuel to the all-solid-state direct carbon solid oxide fuel cells (DC-SOFCs), and, it enables DC-SOFCs to be a novel technology, of high efficient, low cost and environmental friendliness, for distributed power generation.

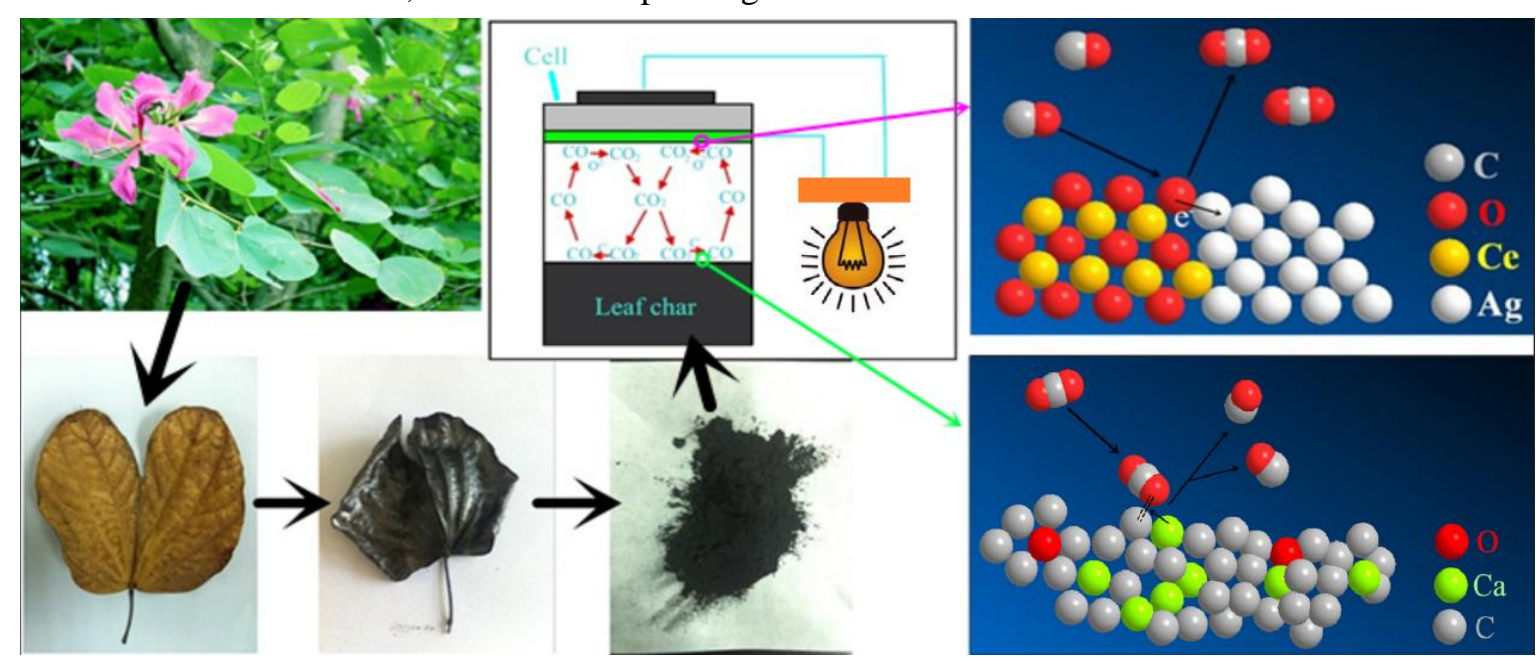

